\title{
Value of an Endogenously Asymmetric Toehold: Estimation of a Dynamic Auction Game
}

\author{
Sudip Gupta* \\ Indian School of Business
}

July 22, 2009

\begin{abstract}
In this paper, we formulate and estimate a dynamic auction game where toehold asymmetry is endogenous. The seller sells multiple goods via a sequence of first price auctions. While bidders are ex-ante symmetric, the first period winner has an informational advantage in the second period bidding game and becomes a strong bidder. This creates an asymmetric informational "toehold" in the second stage. This endogenous toehold creation leads to overbidding in the first period relative to a one period game. We characterize the equilibrium in terms of the observed bid distribution and entry behavior. We suggest a two step estimation procedure to estimate such a dynamic game of toehold creation. The OCS oil tract auctions exhibit one such phenomenon. We apply our method to data on OCS oil tract auctions. We find that the federal government is only recovering $23 \%$ of the 'strong' buyers' willingness to pay in the second period. Bidders perceive the value of information to be at most $12 \%$ of their first period's informational rent. A new semiparametric structural test cannot reject the hypothesis of the strong bidder's informational superiority in the second period and sets it at $18 \%$ relative to the weak bidder. We use the estimates to design alternate mechanisms and empirically show that government's revenue increases when the asymmetry is taken into account in allocating the goods.
\end{abstract}

Keywords: Endogenous Toeholds, Dynamic Auction Estimation, Informational Asymmetry, NonParametric Identification and Estimation, Value of Information, Test of Asymmetry, Copulas.

*Sudip_Gupta@isb.edu. I am indebted to Profs Ken Hendricks, Joris Pinkse and Rob Porter for sharing the data used in this paper. For helpful discussions, without implicating I am thankful to Profs. Siddhartha Bandyopadhyay, Juan Carranza,Yeon Koo Che, Sudipto Dasgupta, Phil Haile, Bruce Hansen, Ali Hortacsu, Sergei Izmalkov, Dennis Kristensen, Jon Levin, David Mcadams, Antonio Merlo, Harry Paarsch, Jack Porter, Lucia Quesada, John Rust, Larry Samuelson, Deepayan Sarkara and seminar participants of the 2005 World Congress of the Econometric Society, seminar participants of the Price College of Business, Oklahoma University, Hong Kong University of Science \& Technology, Smith College of Business. All remaining errors are my own. 


\section{Introduction}

Design of an optimal selling strategy in auctions with toeholds (preoffer ownership stakes in the target) has attracted recent theoretical attentions. A bidder with a toehold may bid aggresively as he wears two hats: a bid price for the object and an ask price for the toehold. In a common value setting, this aggressive bidding makes the winner's curse of winning against a high toehold bidder more severe. The low toehold bidder bids very conservatively in such situations. Since asymmetric toehold gives the bidder some advantage it is likely that bidder would hold an optimal amount of toehold in equilibrium. In this paper we analyze and estimate a dynamic auction game where toehold formation is endogenous under general informational assumptions. A seller sells multiple goods via a sequence of first price auctions. Bidders privately receive signals about the value of the first good from the same distribution. Hence they are informationally symmetric ex ante. However, the winner of the first period auction receives the signal about the following periods' auctioned objects from a 'more informative' distribution relative to other bidders. Hence bidders are informationally asymmetric in the second period. Thus the first period outcome generates asymmetry in the second period distribution of bidders' signals by generating an endogenous "informational" toehold. Thus the first period auction can be seen as a game for formation of asymmetric toeholds for the second period.

The fundamental quest for the optimal selling strategies in this dynamic framework can be analyzed empirically by using the estimates of the distributions of ex-ante valuations of bidders in both periods, the degree of informational (toehold) asymmetry in the second period and the value of the informational toehold in the second period as perceived in the first period. These are typically unobserved to the researcher. In this paper, we estimate these from data on observable bids and entry behaviors using a three step procedure. Specifically, we formulate a dynamic auction model where informational asymmetry of bidders is endogenous. We characterize the equilibrium in terms of the observed bid distribution and entry behavior. We propose a three step procedure to estimate the non-parametric marginal distributions of ex-ante valuations in this dynamic model of entry and bidding by using this characterization and data on bids and entry behavior. Many real life examples like the OCS oil tracts auctions, defence procurements, takeovers battles etc. are examples of this kind of auctions. We apply the model to data from oil tract auctions where the winner of the wildcat tract (first period auction) has more information for the drainage tracts (second period auction). The estimation results and counterfactual experiments suggest that ignoring the dynamic bidding behavior and inherent asymmetry can severely affect seller's revenue.

Informational asymmetry in the second period has an important role to play in the bidding behavior. Here informationaly strong bidder may be characterized as holding a "toehold of information". However note that unlike the standard takeover battles the actual amount of the toehold is not observed by its informationally weak rival. Although who has more information is common knowledge. The bidders privately observe signals about the value of the object from affiliated distributions. Hence the informational toehold influences both the affiliation effect and the winner's curse effect. Winning reveals that ex-post common value of the object is not as good as it was perceived: the winner's curse effect. Winning an object against a bidder who has better informatin makes the winner's curse effect even more severe. However even if the valuation of the object is private, the affiliation of the signals creates another strategic impact in weak bidder's bidding behavior. 
In an affiliated first price sealed bid auction, the perceived probability whether the strong bidder is bidding or not conveys information to the weak bidder. Suppose the joint distribution of strong and weak bidder's signals are affiliated through the value of the object. Then if the strong bidder is not bidding then it conveys to the weak bidder that the intensity of competition is less than what he had thought. This has no bearing on the ex-post value of the object though and can occur in both private and common value environment and termed as the affiliation effect in Pinkse \& Tan (2005). Thus winning against a more informed bidder makes both these effects more severe relative to a symmetric case, hence the informational disadvantaged bidder bids 'timidly' if he believes that the other bidder has better information.

The actual impact of informational asymmetry on bidding behaviors depends on the degree of asymmetry and how related their information is. In this paper, we also propose a new semi-parametric technique to estimate and test the degree of asymmetry based on copula techniques ${ }^{1}$. From a seller's perspective it may not be enough to know who the strong or weak bidders are. It may be necessary to know 'how much stronger' the strong bidder is to design a better selling strategy. The estimated degree of asymmetry is used to conduct counterfactual experiments of alternate selling strategies.

Since informational asymmetry plays a big role in the expected profitability and bidding behavior of bidders in the second period, the ex-ante value of information plays an important role in the bidding behavior in the first period symmetric environment too. The informational asymmetry in the second period is actually determined by the first period outcome. The first period bidding game is like an investment game whose returns are twofold. One part is aimed at winning the first period auction and the second part is aimed at acquiring the informational toehold in the second period. The relative advantage of having more information in the second period guides the relative strength of investing for information in the first period. Examples of investments for information is prevalent in financial and capital investments, production under uncertainty about marginal cost or demand elasticity, auctions, contracting under adverse selection, coordination and search, etc. In this paper, we separately identify and estimate the investment for information behavior from the first period bidding behavior. To the best of my knowledge this paper is the first one to estimate the perceived value of information.

The impact of toehold on bidding behavior in both private and common value setting has been analyzed in Bulow \& Huang and Klemperer ('99), Povel \& Singh ('06), Dasgupta \& Tsui ('03) among others under restrictive informational assumptions like independence for analytical tractability. However if the bidders are bidding for the same object it is likely that a more realistic scenario is where bidders' signals are affiliated. The empirical analysis of this paper works under affiliated signals and interdependence of valuations. A general theoretical analysis under such broad assumptions is not tractable. Our estimation methodology recovers the underlying fundamentals like the unobserved distribution of signals, degree of informational asymmetry. The new equilibrium under a different selling strategy would still be functions of the same fundamentals. We therefore construct counterfactual selling strategies and use the estimated fundamentals

\footnotetext{
${ }^{1}$ Copula is a distribution function which uniquely couples two univariate marginals to their joint distribution function. The copula parameter measures the degree of dependence between two random variable. In a companion paper, Gupta('04), I use copula technique to estimate affiliation as a structural parameter for auction models. Affiliation, a more general concept than correlation, measures the association between bidders' signals and has an important role to play in auction designs.
} 
to compare expected revenues from different selling strategies. We describe which selling strategies could have earned more revenue for the seller under such a general setting. To the best of our knowledge this is the first paper which empirically analyzes endogenous toehold formation under broad informational assumptions.

As an empirical application, we apply the model and methodology developed in this paper to data from oil tract auctions off the coast of Louisiana and Texas ${ }^{2}$. In these auctions, for each geographic location, the government auctions off several oil tracts via sequential first price sealed bid auctions. Thus there are multiple, heterogenous goods for each location and bidders may demand one, more or none of these goods depending on their privately observed signals about the value oil stored. There are two major kinds of oil and gas lease sales. A wildcat sale covers tracts whose geology is not well known and on which exploration involves searching for a new deposit. Firms can get pre bidding seismic informations but no on site drilling is permitted. A drainage sale consists of tracts in areas where a deposit has already been discovered. Onsite drilling is not permitted but firms owning adjacent tracts can conduct off-site drilling, which may be informative about the oil deposited in the tracts to be auctioned. Thus bidders who already have won adjacent tracts have informational advantages over other bidders for drainage tracts. This creates a clear asymmetry among drainage tract bidders, separating them in two categories: strong and weak bidders. Strong bidders are those who own adjacent tracts and have an informational advantage. All other bidders are weak in the sense that their information is less accurate. Thus in the oil tract auctions, informational asymmetry is characterized by the location of the bidders in the second period. This location is determined by the outcome of the first period wildcat bidding, where bidders are informationally symmetric in the sense that they have similar source of signal about the value of the wildcat tract. Hence bidders, while bidding for the wildcat tracts, do not only take their evaluations of the oil storage in the wildcat tracts, but also keep in mind the informational advantages they would get in subsequent sales in that area if they win the current auction. The latter effect generates dynamics in the bidding behavior.

Bidding in wildcat involves a substantial investment as a sunk cost ${ }^{3}$ in conducting and analyzing the seismic survey. This sunk cost creates an 'entry' stage where bidders decide whether to enter to bid for the wildcat tract at all or not based on their initial signals about the tract. In the wildcat sales bidders receive privately observed seismic signals from the same distribution. If the signal is not above a threshold level, then bidding is not optimal. A puzzle so far has been, whether there has been some kind of overbidding as $64 \%$ of wildcat tracts turn out to be $\mathrm{dry}^{4}$. If the fault lay with the accuracy of the seismic surveys, one would have expected them to be carried out less and less as these are quite costly to carry out. However, that has not been seen. One possible explanation of why people bid when they apparently should not is because bidders rationally take into account dynamic considerations. Owning an oil tract, even if it has a high chance to turn out dry, gives the owner an advantage for future drainage sales. Thus, bidders rationally calculate the advantages of bidding in future drainage auction in deciding on optimal bidding strategies in a wildcat auction. These dynamics lower the threshold level of the signal for bidding for wildcat tracts and overstates the expected valuation of the tract. This leads to more entry in the wildcat sales relative to

\footnotetext{
${ }^{2}$ Examples of similar endogenous informational asymmetry also include spectrum auctions, treasury auctions, toeholds and takeovers, defence procurement auctions etc.

${ }^{3}$ The cost of seismic survey runs in millions of US dollars.

${ }^{4}$ Descriptive statistics as reported by Hendricks and Porter ('89).
} 
the static analysis of wildcat auctions. Reduced form analysis suggests that ex-post drainage tract values conditional on ex-post wildcat tract values and competition have a significant positive impact on entry and bidding decisions for wildcat tracts.

We model this phenomena as a three stage dynamic game of mixed discrete and continuous choice. The first stage is an entry game, where bidders make the discrete choice of whether to bid for the wildcat tract or not depending on the privately received pre-bidding seismic signals received. While deciding to enter, they keep the possibility of future asymmetry in mind. This future asymmetry is also taken into account while deciding how much to bid in the wildcat auction in the second stage. While bidding for the third stage drainage auction bidding game, bidders know who is a strong and weak bidder. However, no bidder knows his valuations from the tract perfectly and only receives informative signals. We characterize the equilibrium in each bidding stages in terms of the observed distribution of bids and entry behavior.

The equilibrium bidding functions are monotonic, hence they can be inverted to rewrite the distribution of privately observed ex-ante values in terms of the distribution of bids. We use this to establish non-parametric identification of distribution of privately observed ex ante values (often termed as pseudo values) from the distribution of observed bids. Under standard assumptions, the distributions of pseudo values has a unique mapping to the distribution of privately observed signals.

The structural parameters of the model are the distributions of unobserved pseudo values and the entry parameters (to be described later). We suggest a three step estimation procedure based on the identification results to recover the structural parameters from the data. The estimation involves 'backwards induction'. Specifically, the first order conditions of bidding decisions provide a unique mapping between the distribution of pseudo values and a function of the distribution of observed bids. We first non-parametrically estimate the distribution of pseudo values in the drainage auctions using the equilibrium conditions of drainage bidding. Based on these estimated pseudo values and observed bids, We estimate the expected maximized profit from the drainage auctions. The pseudo values in wildcat auction is characterized as a function of the distribution of wildcat bids and expected maximum profits from the drainage auction. In the second stage, We plug in the estimated maximized profit from drainage auction, estimate the remaining part of this equation nonparametrically from the distribution of observed wildcat bids and get back an estimate of the pseudo values for the wildcat auction. The 'entry' parameters are then estimated by maximizing a likelihood function in the third stage.

The estimates indicate that the federal government is only recovering $23 \%$ of the 'strong' buyers' willingness to pay in the drainage sales. In the wildcat sales, We find that the bidders are willing to pay up to $12 \%$ more to account for possible future informational advantage. The estimates also suggest that weak bidders bid timidly despite having stochastically higher pseudo values and hence win less, which is consistent with the theory and indicates the presence of winner's curse. We use these estimated unobserved ex-ante valuations to conduct counterfactual experiments of different selling strategies for selling such goods and compare the government's revenue.

The rest of the paper is organized as follows: section 2 reviews related literature, section 3 first describes the model and information structure for a simple case of two bidders and characterizes the equilibrium, identification of ex-ante valuations from observed bids are then established for the general model, section 4 
describes the estimation strategy and provides some simulation results, section 5 describes the data and summary statistics, section 6 presents the structural estimation results, section 7 describes the semi-parametric test of asymmetry based on copula, counter-factual experiments are conducted in section 8 , section 9 concludes. All proofs, estimation details and a brief review on copulas are relegated to the appendix.

\section{Related Literature}

Auctions with toehold under private and common value settings and in first and second price auctions has been analyzed in Bukart ('95), Singh ('98), Bulow, Huag \& Klemperer ('99), Dasgupta and Tsui ('03) and Povel \& Singh ('06). Betton and Eckbo ('00) finds that rivals are less likely to bid if the initial bidder has a toehold. All the theoretical analysis work under the independence of signals for analytical tractability. However if the bidders are bidding for the same object it is likely that a more realistic scenario is where bidders' signals are affiliated. The empirical analysis of this paper works under affiliated signals and interdependence of valuations. Also to the best of our knowledge this is the first paper which empirically analyzes endogenous toehold formation.

Asymmetry in auctions has received increased attention recently. McAdams ('06a) characterized equilibria in asymmetric first price auctions under interdependence and affiliated valuations ${ }^{5}$. Under the priority tie breaking rule he established that all equilibria are monotone. Lizzeri \& Persico ('00) established existence and uniqueness in asymmetric auctions with interdependent values where there are only two types of asymmetries. McAdams ('06b) proved uniqueness and existence in a symmetric first price auction with interdependent values. These three papers will be the backbone of our empirical model as identification of unobserved ex-ante valuation from bid data requires monotonic mapping from functions of bid data to ex-ante values. Uniqueness is crucial: if other equilibria exist, then we run the risk of selecting the wrong equilibrium while estimating and hence the policy prescriptions would not be reliable. Other similar works on existence and monotonicity of equilibrium includes Maskin \& Riley ('96 \& '00), Athey('00), Lebrun ('99), Reni \& Zamir ('03). Jofre-Bonet \& Pesendorfer ('03)(JBP) empirically analyzed asymmetry originating from capacity constraints. In their paper, previously won uncompleted contracts (inventory) reduce the probability of winning further contracts. They quantified the efficiency loss due to these intertemporal effects. Asymmetry originating from size difference (Laffont, Oscard, Vuoung ('95), geographic locations (Bajari('99)), among others have also been studied in the literature. However except for JBP no paper has analyzed asymmetry in a dynamic context. Also to the best of my knowledge no paper has analyzed the process of endogenous asymmetry starting from a symmetric environment in a multiple object framework as in this paper. This endogenous asymmetry also endogenizes entry in our model. Endogenous entry, although prevalent in procurement auctions, has received increased theoretical attention recently in Mcaffee('87) and Levin \& Smith ('94) among others. The empirical modelling of entry in this paper is different from theirs and is more related to Berry's ('92) model of entry in the standard industrial organization literature. The

\footnotetext{
${ }^{5}$ Formal definitions are given in later sections. Intuitively, interdependence of valuations arises in cases when one bidder's signal if known to the other bidder also affects his valuation. Affilliation is a broader but similar concept as correlation to depict association between random variables. See later sections and appendix.
} 
entry in this paper is driven by the possibility of endogenous asymmetry and value of information.

Guerre, Perrigne \& Vuong ('00) (GPV) made an important breakthrough in structural non-parametric analysis of auctions. They used the simple and powerful observation that at equilibrium, each bidder is acting optimally against the distribution of his opponents. When bids are observable then both the distribution of the opponent's behavior and the equilibrium (optimal) choice of each bidder is observable. The necessary conditions of monotonic equilibrium in first price auctions characterizes the bidder's unobserved signals in terms of a function of the distribution of observable bids. Under monotonicity these distributions can be inverted to get back the distribution of 'pseudo values' which under assumptions is the distribution of unobserved signals. A non-parametric estimate of this function thus is an estimate of the distribution of unobserved signals or 'pseudo values'. GPV and their coauthors (Li, Perrigne \& Vuong '02) (LPV) in a series of papers established consistency and other properties of this estimate. The semi-parametric analysis in this paper uses their idea and extends it to a dynamic auction setting. Specifically, We add the discrete choice of entry in the decision making process besides the continuous bidding choices. The additional entry stage helps identify and estimate the sunk cost of entry and the pseudo value to the bidder when he expects no other bidder is bidding. These two parameters could not be estimated in the GPV framework as they cancel out in the first order conditions associated with the continuous bidding decision.

The presence of possible asymmetry in drainage tract sales has been widely documented by Hendricks \& Porter ('88,'89,'95) (HP) among others. In their seminal paper (HP'89), they empirically analyzed the case where the strong bidder has perfect information about the value of oil stored in drainage tracts while the weak bidder only receives a public signal. Wilson ('69), Milgrom \& Weber ('83) and HP showed that in such a framework, in equilibrium, the strong bidder plays a pure strategy and makes positive profit while the weak bidder randomizes and makes zero profit. HP's static parametric maximum likelihood analysis does not recover the distributions of unobserved ex-ante values of bidders. The possibility of dynamics in the bidding behavior was also ignored in HP. Clearly, who is strong or weak in drainage auction is actually determined by the outcome of the wildcat auction and rational bidders take this into account while bidding for wildcat tracts. In analyzing the drainage tracts auctions, this paper builds on HP's work and extends it to non-parametrically identify and estimate the distributions of pseudo values of strong and weak bidders non-parametrically under more general assumptions. In this paper, both bidders in drainage auction receive privately observed signals, but the strong bidder is expected to receive a 'more accurate' signal ${ }^{6}$. Since the government knows who the strong and weak bidders are, it may adopt an asymmetric auction mechanism ${ }^{7}$. The counterfactual experiments described in this paper takes this asymmetry into account.

\footnotetext{
${ }^{6}$ Although this assumption will not be imposed while estimating the distributions and would be tested. All I assume is that bidders; whether strong or weak, have some private information which gurantees pure strategy equilibrium.

${ }^{7}$ One such mechanism is giving the weak bidder some advantage in bidding, like if they win they pay only a fraction of their bids.
} 


\section{Model}

\subsection{Description and Information Structure}

For simplicity of exposition, We present the model here for two bidders and two periods. However a generalization to the $N$ bidder case in a multi-period framework is straightforward and will be sketched in the identification and estimation section.

This is a multi-stage game of incomplete information. There is a non-strategic seller (government) who has two indivisible units of the good and sells off each unit of the good in sequential first price auctions. There are two potential buyers 1 and 2. All players are risk neutral. The first period auction is called wildcat auction and the second period is called drainage auctions for reasons described earlier. Bidders receive private signals $s^{w}$ and $s^{d}$ about their valuations of wildcat and drainage auction and bids $b^{w}\left(s^{w}\right)$ and $b^{d}\left(s^{d}\right)$ respectively. Throughout this paper, We will restrict attention to monotonic bidding equilibrium in their signals ${ }^{8}$. The inverse of the equilibrium bidding strategies will be denoted by $\phi=b^{-1}(b(s))$. We assume that the expected value of oil stored in a tract of type $t$ to a bidder $i, U_{i}^{t}$ can be expressed as a function of all bidder's signals, $U_{i}^{t}\left(s_{1}^{t}, s_{2}^{t}\right)=E\left(u_{i}^{t} \mid S_{1}^{t}=s_{1}^{t}, S_{2}^{t}=s_{2}^{t}\right)$, where $t=\{$ wildcat,drainage $\}$ and $u_{i}^{t}$ is bidder $i^{\prime} s$ valuation and is assumed to be non-decreasing in all its arguments, strictly increasing in $s_{i}^{t}$ and twice continuously differentiable. Throughout this paper, the random variables $Y_{i}^{t}$ and $B_{i}^{t}$, will denote the maximum of bidder $i$ 's rival's signal and bid.

This is an interdependent valuation model, as other bidder may posses information that would, if known to a particular bidder, affect the value he assigns to the tract. When bidder's valuation only depend on his signal, $E\left(u_{i}^{t} \mid s_{1}^{t}, s_{2}^{t}\right)=E\left(u_{i} \mid s_{i}^{t}\right)$, then it is called a pure private value model. On the other hand, if $E\left(u_{i}^{t} \mid s_{1}^{t}, s_{2}^{t}\right)$ is increasing in $s_{j}$ for all $j \neq i$, then it is an interdependent value model. Although bidder would like to know his opponents signal in both private and interdependent value framework. The knowledge of opponent's signal affects the expected valuation of the bidder in the interdependent valuation setting whereas the expected valuation remains unchanged in a private value setting even if bidder has private information about his opponent's signal. This effect is generally termed the 'winner's curse'. Roughly speaking, winning the object in an interdependent value setting means that bidder's signal was more optimistic than his opponent's. Rational bidders anticipate this when forming expectation about the value conditional on winning. When the ex-post value is identical for all the bidders then it is called a pure common value model. Since wildcat tract is the first tract to be sold in a specific location, bidders are assumed to have a pure common value for the wildcat tract. However, in drainage tract sales, there is already an informational asymmetry amongst bidders, hence drainage tracts are assumed to have two interdependent values. One value for the strong bidder $\left(v_{1}\right)$ and another value for the weak bidder $\left(v_{0}\right)$. Note that both these values depend on the signal of the other bidder.

The distribution of signals for auction of type $t, F_{t}($.$) are affiliated, in the sense defined { }^{9}$ in Milgrom\& Weber (MW)('82). By affiliation, high value of one signal leads to a higher value of the other signal. Note

\footnotetext{
${ }^{8}$ As will be clear later, under assumptions monotonic equilibrium will be unique.

${ }^{9}$ The concept of affiliation as coined by Milgrom \& Weber ('82), is what is known as Total Positivity (TP) in statistical literature. For two variables, $s_{1}^{\prime} \geq s_{1}, s_{2}^{\prime} \geq s_{2}$, Affiliation is equivalent to $f\left(s_{1}^{\prime}, s_{2}\right) f\left(s_{1}, s_{2}^{\prime}\right) \leq f\left(s_{1}, s_{2}\right) f\left(s_{1}^{\prime}, s_{2}^{\prime}\right)$,
} 
that, independence is a special case of affiliation.

\subsubsection{Information in the Wildcat Auction (First Period)}

Let the value of oil stored in wildcat tract, drawn from $F_{u}$, be denoted by $u$. Bidders are typically symmetric for wildcat auctions in the sense that they privately observe conditionally independent, but affiliated signals $s^{w}$ about $u$ from the same distribution $F_{W}\left(s^{w} \mid u\right)^{10}$.

To economize on notations, let the expected common value of oil stored in an wildcat auction when bidder $i$ with a signal $s_{i}^{w}$, bidding $b_{i}^{w}\left(s_{i}^{w}\right)$ and rival's bid $b_{-i}^{w}$, be given by, $E\left[u_{i} \mid S_{i}^{w}=s_{i}^{w}, b_{-i}^{w} \leq b_{i}^{w}\right]$ where the expectation is taken over the distribution of $u$. Let $E\left[u_{i} \mid S_{i}^{w}=s_{i}^{w}, b_{-i}^{w}=b_{i}^{w}\left(\widetilde{s}_{i}^{w}\right)\right]$ be the 'pivotal' expected value in the sense that a small change of bidder $i$ 's bid will change the winner of the game. Since bidding function is monotonic, it can be rewritten as,

$$
E\left[u_{i} \mid S_{i}^{w}=s_{i}^{w}, b_{-i}^{w}=b_{i}^{w}\left(\widetilde{s}_{i}^{w}\right)\right]=U_{i}^{w}\left(s_{i}^{w}, \widetilde{s}_{i}^{w}\right)=U_{i}\left(s_{i}^{w}, \widetilde{s}_{i}^{w}\right)
$$

Let $U_{0}\left(s_{i}^{w}\right)$ be the expected common value when the bidder does not have any rival. Note that, since wildcat auction is a pure CV auction, due to the presence of 'winner's curse', $U($.$) and U_{0}($.$) need not be the$ same and ordered ${ }^{11}$.

The winner of the wildcat auction becomes a strong bidder in the drainage auction. The relative strongness of bidders' are determined by his location state variable. The location of bidder $i$ evolves according to

$$
D_{i}=\left\{\begin{array}{c}
i \text { is strong, if } i \text { won the wildcat auction in the same location } \\
i \text { is weak, if } i \text { did not win wildcat auction in the same location }
\end{array}\right.
$$

The dynamics of the model is represented by the evolution of the state variable $D$. When bidders are bidding for wildcat tracts they are also choosing their future locations $D$, which affects their marginal distribution of valuations for drainage tracts. Note that, the state variable can also be a continuous distance variable, leading to a continuous type space instead of discrete one as described above.

\subsubsection{Information in the Drainage Auction (Second Period)}

Bidders in drainage auctions are divided into two groups: strong bidder (denoted by 1); who has won the wildcat tract in the first period, and weak bidders (denoted by 0 ); who did not win in the first period. They

equivalently,

$$
\frac{f\left(s_{2}^{\prime} \mid s_{1}\right)}{f\left(s_{2} \mid s_{1}\right)} \leq \frac{f\left(s_{2}^{\prime} \mid s_{1}^{\prime}\right)}{f\left(s_{1} \mid s_{1}^{\prime}\right)}
$$

i.e., $\frac{f\left(.^{\prime} \mid s_{1}^{\prime}\right)}{f\left(. \mid s_{1}\right)}$ is increasing in $s_{1}$ : which is the monotone likelihood ratio property. Thus higher values of $s_{1} \Rightarrow$ higher values of $s_{2}$ more likely It is easy to verify that $f$ is affiliated if and only if, for all $i \neq j$,

For more details see the appendix and MW

$$
\frac{\partial^{2}}{\partial s_{i} \partial \mathbf{s}_{j}} \ln f \geq 0
$$

${ }^{10}$ Thus, each of the random variables $s_{1}^{w}$ and $s_{2}^{w}$ are affiliated with the common component $u$, but conditioned on the common component $u$ they are indepedent.

${ }^{11}$ As noted above, it was not possible to estimate the parameter $U_{0}$ before. The discrepancy between $U$ and $U_{0}$ is an important extreme measure of winner's curse. As will be outlined in later section, I estimate this as a parameter. 
draw their private signals about the value of the drainage tract, $V_{i}$ from different marginal distributions, $F_{1}\left(s_{1}^{d} \mid V_{1}\right)$ and $F_{0}\left(s_{0}^{d} \mid V_{0}\right)$ respectively. Thus $s_{1}^{d}$ is the realization of the random variable $s^{d}$ drawn from the distribution $F_{1}\left(. \mid V_{1}\right)$. Signals $s_{i}^{d} \in \Re$, about the unknown value of oil stored in drainage tracts $V_{i}$ are affiliated in the sense defined before. We assume that all the distributions are continuous. The ex-ante value of the strong bidder is thus given by $v_{1}\left(s_{1}, s_{0}\right)$, and that of the weak bidder be $v_{0}\left(s_{1}, s_{0}\right)$.

Strong bidders evaluate the value of the tract 'better', in the sense that their signals about the value of the tract is more 'accurate' than that of the weak bidder. Thus, if the realization of $v_{1}$ is low then strong bidder's signal $s_{1}^{d}$ is low and vice versa. We do not impose any assumption on the relative ranking of the distributions while deriving the equilibrium first order conditions which will be used for estimation. All We assume is that each bidder has some private informations for the equilibrium to be in pure strategies. The relative ranking of the distributions can be tested using data on ex-post value of the tract and the estimated ex-ante pseudo values.

\subsection{Timeline of Events}

The sequence of moves, for each location, are as follows:

1) Number of potential bidders is common knowledge. Bidders first receive some information; $s_{i}^{w}$, about the value of oil stored in the tract, $u, s_{i}^{w} \sim F^{w}($.$) of the wildcat tract from a seismic survey.$

2 ) There are 2 potential bidders for any location. They simultaneously decide whether to bid for the wildcat auction or not. Bidders receive action specific shocks $\epsilon$ associated with actions of whether to enter or not, drawn independently from Logistic distribution ${ }^{12}$. If they decide to bid they pay a stochastic bid preparation cost $K+\epsilon$ in the current period. The error $\epsilon$ is independent of the seismic survey signals and they are not errors associated with the analysis of seismic surveys. Hence they do not affect the actual amount of bids submitted. These errors are like bidders' action specific shocks, shocks received while going to bid, or following the arguments of Bajari \& Hortacsu ('03) and Mckelvey \& Palfrey ('95); errors made while deciding to bid. Note that no bidder knows his rival's $\epsilon$ or $s^{w}$ while deciding to enter to bid. Let the actual number of bidders be $A$.

3) When bidders submit bids, they do not know whether his rival has decided to submit the bid or not. He also does not know his rival's signal $s_{-i}^{w} . \epsilon$ is independent of $s_{i}^{w}$ and also does not affect the decision of how much to bid. Any bidder submitting a bid $b_{i}^{w}$, wins the auction with probability $\operatorname{Pr}\left(b_{i}^{w}, B^{w}\right)$, where $B^{w}$ is the rival bid ${ }^{13}$.

4) In the following period, bidders decide how much to bid for the neighboring drainage tracts $: b^{d}$. Bidders draw their signals about the valuations of the drainage tract $v_{i}\left(s_{i}^{w}, s_{-i}^{w}\right)$, from continuous asymmetric distributions $F_{i}\left(s^{d} \mid v\right)$. They win the drainage tract with a probability $\operatorname{Pr}\left(b_{i}^{d}, B_{i}^{d}, D\right)$, where $D$ is the state (location) variable of bidder and $B_{i}^{d}$ being the rivals' bid.

We assume that the auctioneer (government), does not act strategically and always sells the objects to the

\footnotetext{
${ }^{12}$ The assumption of logistic distribution is not necessary. However, we adopt this as it will lead to a closed form of the choice probability of whether to enter or not (to be defined later). This will be very handy for the empirical analysis.

${ }^{13}$ In later seections for general case, where we have more than two bidders, $B^{w}$ will be the maximum of his rivals' bid.
} 
highest bidder via two independent first price auctions. We also abstract away from reserve price issues ${ }^{14}$.

In this game bidders have three kinds of choices : a discrete choice of whether or not to bid in an wildcat tract, and a continuous choice of how much to bid for the wild cat tract a second continuous choice of how much to bid for the drainage tract. Thus the number of bidders in an wildcat tract is endogenous. However all the potential bidders bid for a drainage tracts ${ }^{15}$. Thus there is no endogeneity of number of bidders in a drainage tract. Some of them may bid zero though depending on their signals received.

\subsection{Value Function}

The value of the wildcat tract, to the $i^{\text {th }}$ bidder, $V_{i}$, can be written as follows:

$$
V_{i}\left(s_{i}^{w}, \epsilon\right)=\max _{\alpha_{i} \in\{0,1\}}\left\{Q_{0 ; i}\left(s_{i}^{w}\right), Q_{1 ; i}\left(s_{i}^{w}\right)-\epsilon_{i}\right\}, \quad i=\{1,2\}
$$

where $\alpha_{i}=0$ represents not bidding and $\alpha_{i}=1$ represents bidding, $Q_{0}$ is the expected value to the bidder if he decided not to bid for the wild cat auction, and $Q_{1}-\epsilon$ is the expected value of bidding for the wildcat tract. He receives an action specific shock $\epsilon$. We assume that $\epsilon$ 's are independently drawn from a logistic distribution ${ }^{16}$.

Integrating over the $\epsilon_{k}^{\prime} s$, we get the smoothed value function, $V_{i}^{\sigma}$, the value function before the bidder observes his action specific shocks $\epsilon_{k}$ (i.e, before incurring the cost $\epsilon_{k}$ ),

$$
V_{i}^{\sigma}\left(s_{i}^{w}\right)=\int V_{i}\left(s_{i}^{w}, \epsilon\right) d \Phi(\epsilon)
$$

If a bidder decides to bid $b_{i}^{w}\left(s^{w}\right)$ for the wildcat tract, he wins the tract with probability $\operatorname{Pr}\left(b_{i}^{w}, B_{i}^{w}\right)$, when the maximum of his rival's bid $B^{w}$. His next period state will be $D$. Next period he will then bid for the drainage tract in the same location. Let the expected value from bidding for the drainage tract be $T_{i}(D)$, and $\beta$ is the common discount factor.

Now when he is bidding for the wildcat tract he does not know whether his rival is bidding or not. Hence his expected valuations should be weighted by the probability whether he has a rival or not. Let this probability be denoted by $\operatorname{Pr}\left(\alpha_{-i}=1 \mid s_{i}^{w}\right)$, i.e., $\operatorname{Pr}\left(\alpha_{-i}=1 \mid s_{i}^{w}\right)$ is the probability that the rival decides to bid, given bidder has received a signal $s_{i}^{w}$. Observe that,

$$
\begin{gathered}
\operatorname{Pr}\left(\alpha_{-i}=1 \mid s_{i}^{w}\right)=\iint I\left(\alpha_{-i}=1 \mid s_{-i}^{w}, \epsilon_{-i}\right\} d \Phi\left(\epsilon_{-i}\right) d F\left(s_{-i}^{w} \mid s_{i}^{w}\right) \\
=\int \operatorname{Pr}\left(\alpha_{-i}=1 \mid s_{-i}^{w}\right\} d F\left(s_{-i}^{w} \mid s_{i}^{w}\right)
\end{gathered}
$$

\footnotetext{
${ }^{14}$ For the application of OCS auctions in this paper, the average reserve price was US $\$ 15$ per acre the average bid being around US\$600 per acre, the reserve price being not binding it may be safe to assume that there was no reserve price. The estimated ex-ante valuations will be used to formulate an optimum reserve price.

${ }^{15}$ This model is extendable to allow entry in drainage auction too. However, for simplicity I abstract away from entry in drainage tracts.

${ }^{16}$ Integrating over the $\epsilon_{k}^{\prime} s$, we get the smoothed value function, $V_{i}^{\sigma}$, the value function before the bidder observes his action specific shocks $\epsilon_{k}$ (i.e, before incurring the cost for more "infill"),

$$
V_{i}^{\sigma}\left(s_{i}^{w}\right)=\int V_{i}\left(s_{i}^{w}, \epsilon\right) d \Phi(\epsilon)
$$
}


$\operatorname{Pr}\left(\alpha_{-i}=1 \mid s_{-i}^{w}\right)$ is the probability that bidder $i$ perceive that his rival decides to bid, given rival's privately received signal $s_{-i}^{w}$. This is then integrated over $\epsilon_{-i}$ and $s_{-i}^{w}$, given that the $i^{t h}$ bidder received a signal $s_{i}^{w}$; the relevant distribution function being $F_{w}\left(s_{-i}^{w} \mid s_{i}^{w}\right)$, which gives us the probability that bidder $i$ assigns that his rival enters, given that the $i^{t h}$ bidder received a signal ${ }^{17} s_{i}^{w}$. The bidder, conditional on receiving a signals $s_{i}^{w}$, bids $b_{i}^{w}\left(s_{i}^{w}\right)$ to solve the following maximization problem,

$$
\begin{aligned}
Q_{1 ; i}\left(s_{i}^{w}\right)=\max _{b_{i}^{w} \geq 0}\left[\left\{\operatorname { P r } ( \alpha _ { - i } = 1 | s _ { i } ^ { w } ) \left\{\left(U\left(s_{i}^{w}, \widetilde{s}_{i}^{w}\right)-b_{i}^{w}\right) \times \operatorname{Pr}\left(b_{-i}^{w}<b_{i}^{w} \mid s_{i}^{w}\right)-K\right.\right.\right. \\
\left.+\beta \sum_{j=1}^{2} \operatorname{Pr}\left(j \operatorname{wins} W_{A}\right) \int T_{i}(D) d F\left(s^{d}, D\right)\right\} \\
\left.+\operatorname{Pr}\left(\alpha_{-i}=0 \mid s_{i}^{w}\right)\left\{\left(U_{0}\left(s_{i}^{w}\right)-b_{i}^{w}\right)+\beta \int T_{i}(1) d F\left(s^{d}, D=1\right)\right\}\right]
\end{aligned}
$$

The terms within the first curly parentheses represents bidders' expected valuations when he has a rival. The terms within the second curly parentheses represents bidders $i^{\prime} s$ expected valuation when he does not have a rival. Both terms being weighted by the probability of whether he has a rival or not.

$\left\{\left(U()-.b_{i}^{w}\right) \times \operatorname{Pr}\left(b_{-i}^{w}<b_{i}^{w} \mid s_{i}^{w}\right)-K\right\}$ represents bidder $i$ 's expected value from bidding in the wildcat tract, and $T_{i}(D)$ is his expected value from bidding the drainage tract discounted by $\beta, \int T_{i}(D) d F\left(s^{d} \mid v, D\right)$ is the ex-ante value from the drainage auction, before bidders receive their signals about the drainage tracts ${ }^{18}$.

If the bidder decides not to bid for the wildcat tract, he will receive his discounted expected valuation from the drainage tract where for sure he will be a weak bidder if his rival enters this period and otherwise would face the same problem and value $V_{i}^{\sigma}\left(s_{i}^{w \prime}\right)$ again next period ${ }^{19}$. Hence

$$
Q_{0 ; i}\left(s_{i}^{w}\right)=\left\{\beta \operatorname{Pr}\left(\alpha_{-i}=1 \mid s_{i}^{w}\right) \times \int T_{i}(0) d F_{0}\left(s^{d} \mid v\right)+\beta \operatorname{Pr}\left(\alpha_{-i}=0 \mid s_{i}^{w}\right) \times \int V_{i}^{\sigma}\left(s_{i}^{w \prime}\right) d F_{w}\left(s_{i}^{w \prime}\right)\right\}
$$

The expected value from the drainage tract can be written as

$$
T_{i}(D)=\max _{b_{i}^{d} \geq 0}\left\{\left(v_{i}\left(s_{i}^{d}, s_{-i}^{d}\right)-b_{i}^{d}\right) \times \operatorname{Pr}\left(b_{-i}^{d}<b_{i}^{d} \mid s_{i}^{d}, D\right)\right\}
$$

From the bidder's perspective, the drainage tract being auctioned next period. Hence its expected value depends on the next period's state $D$. This in turn depends on bidders choices and outcomes in the wildcat auction this period.

Note that we can write the value function as a mapping into itself.

$$
V_{i}^{\sigma}=\Lambda\left(V_{i}^{\sigma}\right)
$$

Using standard arguments in the literature (see Bhattacharya \& Majumdar ('89), Theorem 3.2,), it can be shown that the mapping $\Lambda$ is a contraction, and a unique solution to the value function exists.

\footnotetext{
${ }^{17}$ Note that using affiliation of $s^{w}$ 's it can be easily shown that, $\operatorname{Pr}\left(\alpha_{-i}=2 \mid s_{i}^{w}\right)$ first order stochastically dominates $\operatorname{Pr}\left(\alpha_{-i}=\right.$ $\left.2 \mid s_{i}^{w \prime}\right)$ for $s_{i}^{w}>s_{i}^{w \prime}$.

${ }^{18}$ Note that

$F\left(s^{d} \mid V_{1}^{d}, D=i\right.$ is strong $)=F_{1}\left(. \mid V_{1}^{d}\right)$, and $F\left(s^{d} \mid V_{0}^{d}, D=i\right.$ is weak $)=F_{0}\left(. \mid V_{0}^{d}\right)$

${ }^{19}$ If the wildcat tract is not sold today then it may be up for sale again in some later date. I assume that if it is up for sale again then it is up for sale as a wildcat tract only.
} 


\subsection{Equilibrium}

We solve for symmetric perfect Bayesian equilibrium in monotone strategies for each stage game. Solution method involves backward induction. We first solve the drainage tract auction as a function of bidders state variable next period $D$. This solution is substituted in the wildcat bidding problem which solves the wildcat auction and determines $D$.

\subsubsection{Last Stage Decision: Analysis of Drainage Tracts}

The distribution of valuations of strong and weak bidders are given by $F_{1}\left(s_{1}\right)$ and $F_{0}\left(s_{0}\right)$ respectively. Note that strong bidder receive more 'accurate' signal as defined before. Let $v_{1}\left(s_{1}^{d}, s_{0}^{d}\right)=E\left[V_{1} \mid S_{1}^{d}=s_{1}^{d}, S_{0}^{d}=s_{0}^{d}\right]$ be the expected value of the tract to bidder 1 , when he received a signal $s_{1}^{d}$ and his rival received a signal $s_{0}^{d}$. $v_{0}\left(s_{1}^{d}, s_{0}^{d}\right)$ is defined analogously. Hence $E\left[V_{1} \mid S_{1}^{d}=s_{1}^{d}, b_{0}^{d}=b_{1}^{d}\left(\widetilde{s}_{1}^{d}\right)\right]=v_{1}\left(s_{1}^{d}, \widetilde{s}_{1}^{d}\right)$ be the pivotal value to bidder 1. $v_{0}\left(s_{0}^{d}, \widetilde{s}_{0}^{d}\right)$ is defined analogously. Bidder's valuations are interdependent. i.e., $v_{i}\left(s_{i}^{d}, s_{j}^{d}\right)$ is non-decreasing in $s_{i}^{d}, s_{j}^{d},\{i, j\} \in\{0,1\}$. Moreover we assume $v_{i}$ is strictly increasing in $s_{i}^{d}$ and $v_{i}(0,0)=0$. The distribution of bidders' signals are affiliated as defined before.

Let the bids by two bidders be $b_{1}^{d}$ and $b_{0}^{d}$ respectively. Let each bidder adopt a monotone bidding strategy $b_{i}^{d}\left(s_{i}\right)$ with an inverse $\phi_{i}\left(b_{i}^{d}\right)=\left(b_{i}^{d}\right)^{-1}\left(b_{i}^{d}\left(s_{i}\right)\right)$. Thus by bidding $b$, the strong bidder wins the auction with probability $\operatorname{Pr}\left(b_{0}^{d} \leq b\right)=G_{0}^{d}(b)=\operatorname{Pr}\left(\phi_{0}\left(b_{0}^{d}\right) \leq \phi_{0}(b)\right)=F_{0}\left(\phi_{0}(b)\right)$, similarly the weak bidder wins the auction with probability $G_{1}^{d}(b)$. Let the common support of the distributions of signals be $[\underline{s}, \bar{s}]$.

Proposition 1 a) With zero probability of ties, there exists a pure strategy equilibrium of the drainage auction in monotonic strategies. It is characterized by the following conditions

$$
\frac{F_{0}^{\prime}}{F_{0}} \phi_{0}^{\prime}\left(b_{1}^{d}\right)=\frac{1}{v_{1}\left(s_{1}^{d}, \theta_{1}\left(s_{1}^{d}\right)\right)-b_{1}^{d}}
$$

and

$$
\frac{F_{1}^{\prime}}{F_{1}} \phi_{1}^{\prime}\left(b_{0}^{d}\right)=\frac{1}{v_{0}\left(\theta_{0}\left(s_{0}^{d}\right), s_{0}^{d}\right)-b_{0}^{d}}
$$

in the common support of signals, i.e., for all $s_{0}, s_{1} \in[\underline{s}, \bar{s}]$, satisfying the boundary conditions, $b_{0}(\bar{s})=$ $b_{1}(\bar{s})=\bar{b}^{d}, b_{0}\left(\underline{s}_{0}\right)=b_{1}\left(\underline{s}_{1}\right)=\underline{b}^{d}$, The equilibrium pair of inverse bid function is given by, $\phi_{i}\left(b^{d}\right)=b_{i}^{-1}\left(b^{d}\right)$, $i \in\{0,1\}$, where $s_{i}^{d}=\phi_{i}(b)$, is the inverse bid function. $\theta_{i}\left(s_{i}^{d}\right)=\phi_{j}\left(b_{i}^{d}\left(s_{i}^{d}\right)\right),\{i, j\} \in\{0,1\}, i \neq j$, is a monotonic function of $s_{i}^{d}$.

Proof. Details are given in the appendix. Here is a sketch, first note that the utility function satisfies the single crossing property and affiliation of signals guarantees that the distribution of valuations is logsupermodular. Moreover, it is assumed that there are zero probabilities of ties. Hence the assumptions of McAdams ('04) is satisfied and a pure strategy equilibrium in monotone strategies exists. The exact characterization of the equilibrium in terms of the differential equations given above then can be found by taking the first order conditions with appropriate boundary conditions ${ }^{20}$.

We call $v_{1}\left(s_{1}^{d}, \theta_{1}\left(s_{1}^{d}\right)\right)$ as the pseudo value of bidder 1 . Let the underlying distribution of $v_{1}\left(s_{1}^{d}, \theta_{1}\left(s_{1}^{d}\right)\right)$ be $F_{1}^{d}$. As $\theta_{i}$ is a monotonic function of $s_{i}^{d}, v_{1}\left(s_{1}^{d}, \theta_{1}\left(s_{1}^{d}\right)\right)$ is distributionally equivalent to $v_{1}\left(s_{1}^{d}, s_{1}^{d}\right)$. Since the

\footnotetext{
${ }^{20}$ It is easy to verify that second order condition is also satisfied.
} 
parameter of interest is the distribution, henceforth with an abuse of notation, We shall write $v_{1}\left(s_{1}^{d}, \theta_{1}\left(s_{1}^{d}\right)\right)$ as $v_{1}\left(s_{1}^{d}, s_{1}^{d}\right)$. Similar arguments holds for $v_{0}\left(\theta_{0}\left(s_{0}^{d}\right), s_{0}^{d}\right)$.

\subsubsection{First Stage Decision: Analysis of Wildcat Auction}

Note that, we have endogenized entry in the wildcat bidding decision by giving each bidder two signals ${ }^{21}$ : $s_{i}^{w}$ and $\epsilon_{i}$. However the random shock $\epsilon_{i}$ is independent of $s_{i}^{w}$ and does not affect the decision of how much to bid. $\epsilon_{i}$ only appears in the decision of whether to bid at all or not. The decision of how much to bid is only affected by the signal of the tract $s_{i}^{w}$. Since $\epsilon_{i}$ is appearing additively in the entering decision, for a given $s_{i}^{w}$ there will be a threshold level of $\epsilon_{i}$, above which not entering is optimal. Similarly it can be shown that, for each $\epsilon_{i}$, there will be a threshold level of $s_{i}^{w}: s_{i}^{w *}$ below which not bidding is optimal ${ }^{22}$. Thus the equilibrium of the entry stage will be characterized by these two thresholds. No bidder observes other bidder's signal in both the entry and bidding stages of the game. Hence they take an expectation of other bidder's signal conditional on his signals. $\epsilon_{i}$ 's are independent across all the bidders, but $s_{i}^{w}$ 's are coming from an affiliated joint distribution of signals for all $i$. The decision to bid for bidder $i$ 's rival $\{-i\}$ as conjectured by $i$, conditioned on the signal received by bidder $i, s_{i}^{w}$ and $\epsilon_{i}$, be given by,

$$
\begin{gathered}
\operatorname{Pr}\left(\alpha_{-i}=1 \mid s_{i}^{w}\right)=\iint I\left(\alpha_{-i}=1 \mid s_{-i}^{w}, \epsilon_{-i}\right\} d \Phi\left(\epsilon_{-i}\right) d F\left(s_{-i}^{w} \mid s_{i}^{w}\right) \\
=\int \operatorname{Pr}\left(\alpha_{-i}=1 \mid s_{-i}^{w}\right\} d F\left(s_{-i}^{w} \mid s_{i}^{w}\right)
\end{gathered}
$$

where $\alpha_{i}$ is the optimum decision of bidder $i$ and $s_{i}^{w}$ is the vector of signals received by bidder $i$. Similarly, the bidder $i$ 's rivals' perception about his entry decision can also be characterized by $\operatorname{Pr}\left(\alpha_{i}=1 \mid s_{-i}^{w}\right)$.

Let $Y^{w}$ be the signal of the rivals bid in the wildcat auction if there is a rival and zero otherwise, then the probability of bidder $i$ wins the auction is the probability that his bid is higher than $Y^{w}$. Let each bidder adopts the monotone bidding strategy $b\left(s^{w}\right)$ with an inverse $\phi\left(b^{w}\right)$.

Then,

$$
\begin{gathered}
\operatorname{Pr}\left(i \text { wins } W_{A}\right)=G_{B_{i}^{w} \mid b_{i}^{w}}^{w}\left(y \mid b_{i}^{w}\right)=\operatorname{Pr}\left(b_{i}^{w}>B_{i}^{w}=\max b_{j}^{w}, \text { for } j \neq i \mid \ni A \text { bidders }\right) \\
=\operatorname{Pr}\left(Y_{i}^{w} \leq \phi\left(b_{i}^{w}\right), \quad \text { for } j \neq i \mid \ni A \text { bidders }\right) \\
=\operatorname{Pr}\left(\alpha_{-i}=1 \mid s_{i}^{w}\right) F^{w}\left(\phi\left(b_{i}^{w}\right)\right)+\operatorname{Pr}\left(\alpha_{-i}=0 \mid s_{i}^{w}\right)
\end{gathered}
$$

where the first line states that the bidder wins the auction if his bid is higher than the maximum of his actual rivals' $(A)$ bid $\left(B^{w}\right)$. The second line uses monotonicity of the bidding strategy ${ }^{23}$ of actual bidders to express distribution of valuations signals in terms of equilibrium bid distribution of the rival bidder $\left(G_{B^{w}}^{w}\left(b_{i}^{w}\right)\right)$. The third line weights these probabilities by the probability of entry of potential bidders. The first term is the probability that the rival enters, in that case bidder $i$ wins with probability $F^{w}\left(\phi\left(b_{-i}^{w}\right)\right)$. The second term is the case when the rival does not enter, in that case, conditional on bidding, bidder $i$ wins with probability one.

\footnotetext{
${ }^{21}$ Biddes decision to enter is a mapping from his signals $\left[s_{i}^{w}, \epsilon_{i}\right]$ to whether to bid or not, $\alpha_{i}=\{0,1\}$.

${ }^{22} \mathrm{~A}$ proof is available from the author.

${ }^{23}$ Note that, when we have endogeneous bidders, as in the wildcat auction, affilation (supermodularity) is not sufficient to ensure the existence of an increasing bid function. Mcaffee, Quan, and Vincent ('02) have analyzed this case and gave a sufficient condition in terms of log-supermodularity. We assume that holds here. We shall come back to it later.
} 
Let $M_{Y^{w} \mid s^{w}}=\operatorname{Pr}\left(\alpha_{-i}=1 \mid s_{i}^{w}\right) F^{w}\left(\phi\left(b_{i}^{w}\right)\right)$, be the distribution of maximum signal of bidder's rival when his rival enters. Let the associated density function be $m_{Y^{w} \mid s^{w}}$. Then,

$$
\begin{aligned}
G_{B^{w} \mid b^{w}}^{w}\left(y \mid b_{i}^{w}\right) & =M_{Y^{w} \mid s^{w}}\left(Y_{i}^{w} \mid s_{i}^{w}\right)+\operatorname{Pr}\left(\alpha_{-i}=0 \mid s_{i}^{w}\right) \\
& =M_{Y^{w} \mid s^{w}}\left(\phi\left(B_{i}^{w}\right) \mid \phi\left(b_{i}^{w}\right)\right)+\operatorname{Pr}\left(\alpha_{-i}=0 \mid \phi\left(b_{i}^{w}\right)\right)
\end{aligned}
$$

Let $g^{w}$ be the density function associated with $G^{w}$.

Lemma 2 The equilibrium bidding rule of the wildcat bidding game can be characterized by the following equations:

$b_{i}^{w}=U\left(s_{i}^{w}, s_{i}^{w}\right)-\left[M_{Y^{w} \mid s^{w}}\left(s_{i}^{w} \mid s_{i}^{w}\right)+\operatorname{Pr}\left(\alpha_{-i}=0 \mid s_{i}^{w}\right)\right] \times \frac{b^{\prime}\left(s_{i}^{w}\right)}{m_{Y^{w} \mid s^{w}}\left(s_{i}^{w} \mid s_{i}^{w}\right)}+\beta \int[T(1$ is strong $)-T(1$ is weak $)] d F\left(s^{d}, D\right)$

with the terminal condition, $b_{i}^{w}\left(s^{w^{*}}\right)=0$, and writing in terms of the distribution of bids,

$$
b_{i}^{w}=U\left(s_{i}^{w}, s_{i}^{w}\right)-\frac{G_{B^{w} \mid s^{w}}^{w}\left(b_{i}^{w} \mid b_{i}^{w}\right)}{g_{B^{w} \mid s^{w}}^{w}\left(b_{i}^{w} \mid b_{i}^{w}\right)}+\beta \int[T(1 \text { is strong })-T(1 \text { is weak })] d F\left(s^{d}, D\right)
$$

Proof. In the appendix.

The first order condition states that bid equals expected valuation plus a mark down and plus a markup. The markdown accounts for the level of competition in the wildcat sale. The mark up accounts for the discounted future rent from winning the wildcat today, expressed as the relative advantage of being a strong bidder. We refer this as the perceived value of information of being a strong bidder in the drainage tract.

Now note that if we plug the equilibrium bidding decisions in the choice specific value functions $Q_{1}$ and $Q_{0}$, we get the equilibrium values of these. The presence of the future rent in wildcat values thus increases the attractiveness of the wildcat tract. In the entry stage of deciding to bid there is a threshold level of signal below which not bidding is optimal. The presence of positive future rent would thus reduce this threshold level of signal relative to the scenario when there is not drainage tract. It is thus obvious to say that there will be more entry in the wildcat tract bidding when there is drainage auctions relative to the fact when there is no drainage auction.

\subsection{Identification}

\subsubsection{Identification of Valuations in the Drainage Auctions}

In this section we establish the identification of the distribution of signals from the observed bidding behavior of bidders for the drainage and wildcat auctions respectively. Note that, for simplicity of exposition, in our theoretical analysis we have so far assumed that there are only two bidders. For the identification and estimation of the OCS auction data we generalize the first order conditions to more than two bidders below. We assume that there are two types of bidders in the drainage auctions. There are 1 strong bidder ${ }^{24}$ (type 1 ) and $n_{0 d}$ weak bidders (type 0 ). Note that the set $n_{0 d}$ is endogenous. It is determined by who did not win

\footnotetext{
${ }^{24}$ Note that, by our formulation there is only one strong bidder in any drainage tract. However it may be possible to have more than one strong bidder. For example, in general there are eight drainage tracts, and if the winner of the first and second
} 
in the wildcat auction. However, before bidding for the drainage auctions, bidders (and the econometrician) can observe who are strong and weak bidders ${ }^{25}$.

Let

$$
v_{1}\left(s_{1}^{d}, y_{1 i}^{d}, y_{0 i}^{d}, n\right)=E\left[V_{1 i}^{d} \mid S_{1}^{d}=s_{1}^{d}, Y_{0}^{d}=\max _{j \in W e a k} s_{0 j}^{d}=y_{0 i}^{d}, n=1+n_{0 d}\right]
$$

be the expected value to bidder $i$ of type 1 when he received a signal $s_{1 i}^{d}$ and the maximum signal of his rival of type 0 be $y_{0 i}^{d}$, where the expectation is taken over the distribution of $V_{1 i}$.

Similarly, let

$$
v_{0 i}\left(s_{0 i}^{d}, y_{1 i}^{d}, y_{0 i}^{d}, n\right)=E\left[V_{0 i}^{d} \mid S_{0 i}^{d}=s_{0 i}^{d}, Y_{1}^{d}=s_{1}^{d}=y_{1}^{d}, Y_{0}^{d}=\max _{j \in W e a k, i \neq j} s_{0 j}^{d}=y_{0 i}^{d}, n\right]
$$

be the expected value to bidder $i$ of type 0 when he received a signal $s_{0 i}^{d}$ and the maximum signal of his rival of type 0 be $y_{0 i}^{d}$, and that of the strong bidder be $y_{1}^{d}$.

This is thus a interdependent valuations model. Both type of bidders may benefit from learning the signals of the other type. There is only one strong bidder in this model. However the number of weak bidders can be more than one depending on the set of potential bidders of the wildcat auction.

Note that bidders are asymmetric across the groups but symmetric within each group. Hence $v_{0 i}\left(s_{0 i}^{d}, y_{1 i}^{d}, y_{0 i}^{d}, n\right)=$ $v_{0}\left(s_{0 i}^{d}, y_{1 i}^{d}, y_{0 i}^{d}, n\right)$, for all $i \in$ Type 0 . We assume $v_{k}\left(s_{i k}^{d}, y_{k i}^{d}, y_{j i}^{d}, n\right)$ is non-decreasing in $s_{i k}^{d}, y_{k i}^{d}, y_{j i}^{d}$, for all $i$, and $j \neq k,\{j, k\} \in\{0,1\}$. Moreover we assume that $v_{k}$ is strictly increasing in $s_{i k}^{d}$ and $v_{k}(0,0,0,)=$.0 . For notational simplicity we will suppress the argument $n$ below.

The 'strong' bidder receives a private signal ${ }^{26} s_{1 i}^{d}$ about his unknown valuation $v_{1}^{d}$ and chooses $b_{1 i}^{d}$ to maximize $E\left[\left(v_{1 i}-b_{1 i}^{d}\right) I\left(B_{-i}^{d} \leq b_{1 i}^{d}\right) \mid s_{1 i}\right]$, where $B_{-i}^{d}$ is the maximum of his rivals' bid. Thus $B_{-i}^{d}=$ $\max _{i}\left\{b_{0 i}^{d}\left(s_{0 i}\right)\right\}$, and $y_{0 i}=\max _{j} s_{0 j}^{d}$. and $b_{1 i}^{d}($.$) and b_{0 i}^{d}($.$) are the equilibrium strategies of 'strong' and 'weak'$ bidders respectively. I restrict our attention to symmetric, strictly increasing and differentiable equilibrium strategies ${ }^{27}$. By 'symmetry' we mean symmetry within each sub-group of weak bidders. Let $B_{1}^{d}=b_{1}^{d}$, and $B_{0}^{d}=\max _{i} b_{0 i}^{d}$, let $G_{B_{1}^{d}, B_{0}^{d} \mid b_{0}^{d}}(X, X \mid x)$ and $G_{B_{0}^{d} \mid b_{1}^{d}}$ be the distribution of bids. Then,

Lemma 3 The first order conditions associated with bidder's optimization problems can be written as; for the strong bidders

$$
v_{1}^{d}\left(s_{1 i}^{d}, y_{0 i}=s_{1}^{d}\right)=b_{1}^{d}+\frac{G_{B_{0}^{d} \mid b_{1}^{d}}\left(b_{1}^{d}, b_{1}^{d} \mid b_{1}^{d}\right)}{d G_{B_{0}^{d} \mid b_{1}^{d}}\left(b_{1}^{d}, b_{1}^{d} \mid b_{1}^{d}\right) / d X}=\xi_{1}^{d}\left(b_{1}^{d}, G\right)
$$

Similarly for the weak bidders,

$$
v_{0}^{d}\left(s_{0 i}^{d}, s_{0 i}^{d}, s_{0 i}^{d}\right)=b_{0}^{d}+\frac{G_{B_{1}^{d}, B_{0}^{d} \mid b_{1}^{d}}\left(b_{0}^{d}, b_{0}^{d} \mid b_{0}^{d}\right)}{d G_{B_{1}^{d}, B_{0}^{d} \mid b_{1}^{d}}\left(b_{0}^{d}, b_{0}^{d} \mid b_{0}^{d}\right) / d X}=\xi_{0}^{d}\left(b_{0}^{d}, G\right)
$$

drainage tract auctions are different then in the third drainage tract auction there are 2 strong bidders. However, for this paper by assumption all the drainage tract are sold on the same date which rules out such a possibility. Selling of all drainage tracts on the same date does not literally means they are sold on the same day. All it requires that there is not enough time in between two drainage sales for information transmission to the winner of the earlier sale.

${ }^{25}$ The econometrician can observe the latitude and longtitude of the wildcat and drainage tracts, the saledate of the tracts and the identity of the bidders. A strong bidder is someone who has one the nearest (defined by latitude and logitude) wildcat tract, sold before the drainage tract.

${ }^{26}$ Note that, the signals are affiliated and hence so are $s_{i k}^{d}, y_{k i}^{d}$ and $y_{j i}^{d}$.

${ }^{27}$ The existence and uniqueness issue of such equilibrium has been discussed in McAdams ('04) and Lizzeri \& Persico ('00). 
with the boundary conditions $\underline{b}_{0}^{d}\left(\underline{s}_{0}^{d}\right)=\underline{b}_{1}^{d}\left(\underline{s}_{1}^{d}\right)=0$.

Proof. In the appendix.

Note that, for fixed number of bidders, since $v_{1}^{d}\left(s_{1 i}^{d}, s_{1}^{d}\right)$ and $v_{0}^{d}\left(s_{0 i}^{d}, s_{0 i}^{d}, s_{0 i}^{d}\right)$ are monotonic functions of its arguments, the distributions of $v_{1}($.$) and v_{0}($.$) will be the distribution of s_{1}($.$) and s_{0}($.$) . However, it should$ be noted that, $v_{1}($.$) and v_{0}($.$) depends on the number of bidders due to the presence of interdependence of$ valuation and the winner's curse, and the above generalization cannot be imposed if the number of bidders varies. Also even if the number of bidders remains fixed, then as has been shown in Athey \& Haile ('02) and others, the joint distribution of signals $s_{1}($.$) and s_{0}($.$) and values v_{1}($.$) and v_{0}($.$) are not identified { }^{28}$. These can be identified if additional structures are imposed as in Li, Perrigne and Vuong ('00) or ex-post values are available as in Hendricks, Pinkse and Porter ('03). For the oil tract dataset analyzed in this paper, we have ex-post values available and identification would follow. Since the parameters of interests are the distributions of the ex-ante values, we abstract away from these issues and without loss of generality refer the distribution of ex-ante values $v_{1}($.$) and v_{0}($.$) as F_{1}^{d}($.$) and F_{0}^{d}($.$) respectively. Similar arguments hold$ for the wildcat signals. Readers are referred to the above references for more discussions.

The following lemma establishes the identification of distribution of interdependent values $v_{1}$ and $v_{0}$, $F^{d}\left(v_{1}, v_{0}\right)$ from bid distribution.

Lemma 4 The affiliated distribution of interdependent values for the drainage auction are non-parametrically identified from the observed bids.

Proof. In the Appendix.

\subsubsection{Identification of Valuations in the Wildcat Auctions}

The first order conditions associated with the Bayesian equilibrium strategies for the bidders who have already entered to bid in the wildcat auction is given by

$$
U\left(s_{i}^{w}, s_{i}^{w}\right)=b_{i}^{w}+\frac{G_{B_{w} \mid s_{w}}^{w}\left(b_{i}^{w} \mid b_{i}^{w}\right)}{g_{B_{w} \mid s_{w}}^{w}\left(b_{i}^{w} \mid b_{i}^{w}\right)}-\beta \int[T(1 \text { is strong })-T(1 \text { is weak })] d F\left(s^{d}, D\right)
$$

where $U\left(s_{i}^{w}, s_{i}^{w}\right)$ is the expected common value of the tract to bidder $i$ when he received a signal $s_{i}^{w}$, and the maximum of his rival's signal ${ }^{29}$ is also $s_{i}^{w}$.

Lemma 5 Given $\beta$, the distribution of $U$ from the common value model for wildcat auction is identified for the bidders who submitted bids, from the observed distribution of bids and the data on actual and potential number of bidders.

Proof. In the Appendix.

\footnotetext{
${ }^{28}$ The intuition is very simple, there are only $n$ bid equations and the number of variables to be identified are $n+2$.

${ }^{29}$ Since there could be more than two bidders, the maximum of the rival's signal is what is important to the bidder to account for the winner's curse in equilibrium.
} 


\section{Estimation Strategy}

The structural parameters of interest are the distributions of ex-ante values $F^{w}, F_{1}^{d}, F_{0}^{d}$, and the entry parameters $K$, and $U_{0}$. The observables of the model are the distribution of bids of wildcat and drainage auctions and the identity of bidders. The estimation of our model will follow the three stage backward induction procedure used to establish the equilibrium. In the first stage, using the first order conditions and the distribution of bids from the drainage auctions, we estimate $F_{1}^{d}, F_{0}^{d}$ non-parametrically. In the second stage, using the estimated distributions in the first stage and first order conditions and the distribution of bids from the wildcat auctions we estimate $F^{w}$ non-parametrically. In the third stage, the 'entry parameters' $K$ and $U_{0}$ can be estimated ${ }^{30}$ using the estimates of the previous two stages and the observed entry behaviors of potential bidders in each location.

First Stage : In the first step, we estimate the bid distributions from the drainage auctions for a particular location and recover the 'pseudo' values using the equations (10) and (11). Note that the right hand side of both these equations are represented in terms of the distributions of observed bids. we first estimate $\frac{G_{B_{0}^{d} \mid b_{1}^{d}}\left(b^{d} \mid b_{1}^{d}\right)}{d G_{B_{0}^{d} \mid b_{1}^{d}}\left(b_{1}^{d} \mid b_{1}^{d}\right) / d X}$ and $\frac{G_{B_{1}^{d}, B_{0}^{d} \mid b_{0}^{d}\left(b_{0}^{d}, b_{0}^{d} \mid b_{0}^{d}\right)}}{d G_{B_{1}^{d}, B_{0}^{d} \mid b_{0}^{d}}\left(b_{0}^{d}, b_{0}^{d} \mid b_{0}^{d}\right) / d X}$. Note that, the ratio in (11) can be interpreted as

$$
\frac{\operatorname{Pr}\left(B^{d} \leq b_{0}, B_{0}^{d} \leq b_{0}, b_{0}=b_{0}\right)}{\operatorname{Pr}\left(B^{d}=b_{0}, B_{0}^{d} \leq b_{0}, b_{0}=b_{0}\right)+\operatorname{Pr}\left(B^{d} \leq b_{0}, B_{0}^{d}=b_{0}, b_{0}=b_{0}\right)}
$$

The standard procedure for estimation as developed in GPV('00) or LPV('02) does not apply here as when there is a strong bidder and $n_{0}^{d}$ is strictly positive then the terms above involves a trivariate distribution and a total derivative, see Campo, Perrigne and Vuoung ('03) for more details.

Denoting the non-parametrically estimated numerator by $\widehat{G}_{B_{1}^{d}, B_{0}^{d}, b_{0}^{d}}\left(b_{0}^{d}, b_{0}^{d}, b_{0}^{d}\right)$ and the denominator by $\widehat{D}_{01}\left(b_{0}^{d}, b_{0}^{d}, b_{0}^{d}\right)+\widehat{D}_{02}\left(b_{0}^{d}, b_{0}^{d}, b_{0}^{d}\right)$, the interdependent values for the weak bidder in the drainage auctions can be estimated as,

$$
\widehat{v}_{0}^{d}(.)=b_{0}^{d}+\frac{\widehat{G}_{B^{d}, B_{0}^{d}, b_{0}^{d}}\left(b_{0}^{d}, b_{0}^{d}, b_{0}^{d}\right)}{\widehat{D}_{01}\left(b_{0}^{d}, b_{0}^{d}, b_{0}^{d}\right)+\widehat{D}_{02}\left(b_{0}^{d}, b_{0}^{d}, b_{0}^{d}\right)}=\widehat{\xi}_{0}^{d}\left(b_{0}^{d}, G\right)
$$

Similarly that of the strong bidder can be estimated as,

$$
\widehat{v}_{1}^{d}(.)=b_{1}^{d}+\frac{\widehat{G}_{B_{1}^{d}, B_{0}^{d}, b_{1}^{d}}\left(b_{1}^{d}, b_{1}^{d}\right)}{\widehat{D}_{11}\left(b_{1}^{d}, b_{1}^{d}\right)}=\widehat{\xi}_{1}^{d}\left(b_{1}^{d}, G\right)
$$

Plugging in these values in the objective function we get upper bound of the expected maximum values of strong and weak bidders $T_{1}$ and $T_{0}$ respectively. (Details are given in the appendix.) The integration is evaluated numerically.

\section{Second Stage}

In the second stage we first non parametrically estimate the bid distributions for each wildcat sales $G^{w}$ and $g^{w}$ respectively. These and upper bounds of $T_{1}-T_{0}$ are then plugged in the following first order equation characterizing the equilibrium, to get the upper bound of 'pseudo' values,

\footnotetext{
${ }^{30}$ The analysis and testing in this paper requires only the distributions of ex-ante values $F^{w}, F_{1}^{d}, F_{0}^{d}$. I donot estimate the entry paremeters in this paper. Under the assumptions of affiliated private values drainage auctions, I estimated the entry parameters in Gupta('03).
} 


$$
\widehat{U}\left(s_{i}^{w}, s_{i}^{w}\right)=b_{i}^{w}+\frac{G_{B^{w} \mid s^{w}}^{w}\left(b_{i}^{w} \mid b_{i}^{w}\right)}{g_{B^{w} \mid s^{w}}^{w}\left(b_{1}^{w} \mid b_{1}^{w}\right)}-\beta \int[T(D=1)-T(D=0)] d F\left(s^{d}, D\right)
$$

\section{Third Stage}

The first two stages estimates the major structural parameters: (the distribution of pseudo values of drainage and wildcat tracts bidders), relevant for the analysis of this paper. The two unknowns of the model are now the entry parameters $K$ and $U_{0}$. Although we do not report the estimates here ${ }^{31}$, but outline a procedure to estimate these based on the data from entry behavior. Note that, the estimated distribution of pseudo values from the drainage and wildcat auctions help us calculate the choice specific value functions $Q_{2 ; i}\left(s_{i}^{w} ; K, U_{0}\right)$, and $Q_{1 ; i}\left(s_{i}^{w}\right)$.Since the distributions of the pseudo values are estimated, the problem to the econometrician is the problem faced by the rival bidder if he had also observed the signals received by bidder $i$ and the only uncertainty is the unknown $\epsilon_{i}$. Since $\epsilon$ 's follow iid logistic distribution, the choice probability of entering by bidder $i$, is given by

$$
\begin{aligned}
\operatorname{Pr}\left(\alpha_{i}\right. & \left.=1 \mid s_{i}^{w}\right)=\operatorname{Pr}\left(Q_{1 ; i}\left(s_{i}^{w}\right)-\epsilon_{i} \geq Q_{0 ; i}\left(s_{i}^{w}\right) \mid s_{i}^{w}\right) \\
& =\frac{\exp \left(Q_{1 ; i}\left(s_{i}^{w}\right) / \rho\right)}{\sum_{k=1}^{2} \exp \left(Q_{k ; i}\left(s_{i}^{w}\right) / \rho\right)}
\end{aligned}
$$

The choice probabilities of entry can be used to form the likelihood function

$$
\operatorname{Lik}\left(K, U_{0} \mid .\right)=\prod_{l=1}^{L} \prod_{i=1}^{n} p_{l}^{*}\left(s_{i}^{w} ; K, U_{0}\right)
$$

where $L$ is the number of wildcat auctions. Maximization of these likelihood function can be matched to the observed entry behavior ${ }^{32}$ to give estimates of the parameters ${ }^{33}\left(K, U_{0}\right)$.

\subsection{Practical Issues}

The observed distribution of bids is in general highly skewed with a large number of observations in the lower end. We therefore apply log- transformation to the distribution of bids. The logarithm transformation to the distribution of bids translates equations (23) and (24) to

$$
\begin{gathered}
v_{1}^{d}=\exp \left(c_{1}^{d}\right)\left(1+\frac{G_{C_{0}^{d} \mid c_{1}^{d}}\left(c_{1}^{d} \mid c_{1}^{d}\right)}{d G_{C_{0}^{d} \mid c_{1}^{d}}\left(c_{1}^{d} \mid c_{1}^{d}\right) / d X}\right)-1=\tau_{1}^{d}\left(c_{1}^{d}\right) \\
v_{0}^{d}=\exp \left(c_{0}^{d}\right)\left(1+\frac{G_{C_{1}^{d}, C_{0}^{d * d} \mid c_{0}^{d}}\left(c_{0}^{d}, c_{0}^{d} \mid c_{0}^{d}\right)}{d G_{C_{1}^{d}, C_{0}^{d * d} \mid c_{0}^{d}}\left(c_{0}^{d}, c_{0}^{d} \mid c_{0}^{d}\right) / d X}\right)-1=\tau_{0}^{d}\left(c_{0}^{d}\right)
\end{gathered}
$$

\footnotetext{
${ }^{31}$ Estimation results can be found in $\operatorname{Gupta}(03)$, where I also estimated the entry stage parameters under the assumption that the drainage auctions are affiliated private value auctions.

${ }^{32}$ The observed entry behavior requires a knowledge of the potential bidders to the researcher. The standard definition of potential as defined by HP can be used to get a rough estimate.

${ }^{33} \mathrm{We}$ assume that the expected value of the tract if there are no rival bidder is constant across auctions, i.e., $U_{0}$ is constant across $L$.
} 
where $c=\log (1+b), G_{C_{1}^{d}, C_{0}^{d} \mid c_{1}^{d}}\left(c_{1}^{d}, c_{1}^{d} \mid c_{1}^{d}\right)$ is the conditional density of $\left(C_{1}^{d}, C_{0}^{d}\right)=\left(\max _{i \neq 1} \log (1+\right.$ $\left.\left.b_{1 i}^{d}\right), \max _{i} \log \left(1+b_{0 i}^{d}\right)\right)$ given $\log \left(1+b_{1}^{d}\right), c_{1}$ being chosen arbitrarily among $n_{1}$ values, and $d G_{C_{1}^{d}, C_{0}^{d} \mid c_{1}^{d}}\left(c_{1}^{d}, c_{1}^{d} \mid c_{1}^{d}\right) / d X$ is the appropriate total derivative.

Since Kernel density estimators are not well estimated close to the boundaries of their support ('boundary effect'), we use trimming as used in GPV and LPV. Specifically, for each $n_{i}$,

$$
\begin{array}{rlrl}
\widehat{v}_{i l}^{d} & =\tau_{i}\left(c_{i l}\right) \text { if } & h_{i} \leq c_{i l} \leq b_{\max }-h_{i} \\
& =\infty & & \text { otherwise }
\end{array}
$$

for $i=\{0,1\}, l=1,2, \ldots L$.

Similar log-transformations and trimming is applied to data on wildcat bids too.

The marginal densities of $\widehat{v}_{i}^{d}$ is estimated by

$$
\widehat{f}\left(\widehat{v}_{i l}^{d *}\right)=\frac{1}{h_{g_{i}}^{2} n_{i}^{d} L} \sum_{l=1}^{L} K\left(\frac{x-\widehat{v}_{i l}^{d *}}{h_{g_{1}}}\right)
$$

\subsection{Choice of Bandwidths and Kernels}

Uniform consistency of the estimation of the 'pseudo values' requires compact kernels and specific bandwidth rates (see GPV). We use triweight Kernels as has been used in the literature (see GPV, LPV). The choice of bandwidths requires more attention. We follow the literature (GPV,LPV) in choosing the bandwidths: $h=c(n L)^{-1 / 5}$, and $c=2.978 \times 1.06 \widehat{\sigma}_{d}$, where $\widehat{\sigma}$ is the standard deviation of bids.

\subsection{Standard Errors and Design of Dependent Bootstrap Sample}

The estimation methodology outlined above is complex and non trivial. The first and second stages of the estimation of the distibution of signals is nonparametric.. However the signals are unobserved and is estimated using the equilibirum conditions. The standard asymptotic distribution theory of nonparametric estimation need not go through here. The estimation errors of the first ad second stage should also affect the entry probabilities in the third stage and hence the standard error of the parameters. In the absense of an theretical asymtototic distributions we use bootstrap to compute the standard errors of the parameters. The standard iid bootstrap procedure also is not applicable here. Note that the drainage tracts are following a particular wildcat tracts and one bidder in one auction should not be coupled with any bidder of another auctions as the strategies in different auctions could be different. Thus there is two types of dependencies: within auction bidder dependency and wildcat and drainage auction dependency. We therefore apply dependent bootstrap. The bootstrap procedure works as follow:

1. choose different draniage auctions independently for boot times $_{1}$

- choose all the bidders in the same drainage auction as a block

2. for each boot 1 sample perform first stage estimation and get the distribution of signals for drainage bidders 
3. choose the same wildcat auction that these drainage tracts were originally associatecd with

- perform the second stage estimation and the distribution of signals for wildcat bidders

4. choose the same potentian bidders for the entry stage:

- perform the likelihood based estimation of entry parameters (sunk cost $K$ and $U_{0}$ )

5. perform steps 1 through 4 boot $_{1}$ times

6. compute the bootstrap standard errors of $K$ and $U_{0}$ based on the above procedure

\subsection{Monte Carlo Simulation}

\subsubsection{Simulation of Drainage Auction}

The analytical solution of asymmetric model is available only for very special cases. We adopt the solution presented in Krishna ('02) to generate distribution of bids and recover the pseudo values from there. We perform this simulation for two bidders assuming that $v_{i}\left(s_{i}, s_{i}\right)=s_{i}$. This is an asymmetric private value model and is a special case of affiliated interdependent value. However, the estimation methodology is same for both. We assume that strong bidder's pseudo valuation $v_{1}$ is distributed uniformly in $\left[0, w_{1}\right]$ and that of weak bidder be distributed uniformly $\left[0, w_{2}\right]$. Note that, here the strong bidder's valuation stochastically dominates that of the weak bidder, which is a special case of the assumption of strongness used in this paper. Krishna has shown that in this case the closed form solution for the bidding rule is,

$$
b_{i}^{d}\left(v_{i}\right)=\frac{1}{k_{i} v_{i}}\left(1-\sqrt{1-k_{i} v_{i}^{2}}\right)
$$

where $k_{i}=\frac{1}{w_{i}^{2}}-\frac{1}{w_{j}^{2}}, i=\{1,2\}$.

We set $w_{1}=\frac{4}{3}$ and $w_{2}=\frac{4}{5}$, and generate $L=100$ draws from the respective uniform distributions to generate the bid data using the above equation. We then estimate the 'pseudo values' by the methods described above for the drainage auction. We use a triweight kernel and bandwidths used in Campo, Perrigne \& Vuoung ('03). We present the estimated distribution of 'pseudo values' in the graph. More specifically, we used the following bandwidth $h_{1}=c_{1}\left(n_{1} L\right)^{-1 / 5}$, and $h_{2}=c_{2}\left(n_{0} L\right)^{-1 / 6}, c_{1}=2.978 \times 1.06 \widehat{\sigma}_{d_{1}}$, $c_{2}=2.978 \times 1.06 \widehat{\sigma}_{d_{2}}$.

The estimated bid distribution function is plotted in figure 1 and compared with the actual distribution.

$$
\text { Insert Figure } 1 \text { About Here }
$$

The smoothed densities are plotted in figure 2. Except for some wiggles towards the end both the densities match each other quite well and fall within the bootstrap band. A Kolmogorov Smirnov test of equality of densities cannot be rejected with a $p$-value 0.47 . The corresponding bootstrap $p$-value was 0.43 .

Insert Figure 2 About Here 
The summary statistics of the true value, estimated value and errors are presented below.

Table1 : Descriptive Statistics of Simulation

\begin{tabular}{lcc}
\hline \hline & True Value & Estimated Value \\
\hline Minimum & 0.01 & 0.01 \\
1st Quantile & 0.33 & 0.28 \\
Median & 0.67 & 0.55 \\
Mean & 0.66 & 0.62 \\
3rd Quantile & 0.95 & 0.94 \\
Maximum & 1.31 & 1.48 \\
\hline
\end{tabular}

\section{$5 \quad$ Data and Summary Statistics}

We apply the model to data ${ }^{34}$ on sales of wildcat and drainage tracts off the coasts of Texas and Louisiana held since 1954. The government sells off these tracts to the highest bidder via a sealed bid auction and charges his bid (first price auction). Bidder for these tracts are oil companies. Before firms conduct tract specific seismic surveys, a set of tracts are nominated based on some area wide pre-sale exploration. Government constructs a final list based on the nominations. Many more tracts are nominated than receive bids, and the nomination process probably contains no information. Nominated tracts are then sold in a first price sealed bid auction. The winning bidder has five years to explore a tract. If no exploration is done in 5 years then the lease reverts back to the government and the tract may subsequently be reoffered. If oil or gas is discovered in sufficient quantities then the lease is automatically renewed as long as production occurs.

For each tract the data set contains the date of sale; acreage; location (Latitude and Longitude); the identity of all bidders and the amounts they bid; whether the government accepted the high bid; the number, date and depth of any wells that were drilled; monthly production of oil, condensate, natural gas and other hydrocarbons through 1991. The dataset also have information on drilling costs of wildcat and production wells obtained from annual surveys by the American Petroleum Institute. Typically an wildcat tract consists of 5000 to 5760 acres and covers on an average 0.0463 degrees of longitude and 0.0405 degrees of latitude. There are generally eight drainage tracts surrounding an wildcat tract and each one covers around 2500 acres. The strong and weak bidders are identified using their firm code and the latitude and longitude information of the tracts. Specifically, a strong bidder for a drainage tract is a bidder who has owned the nearest wildcat tract in the neighborhood before the drainage tract is up for sale.

A detailed description of the dataset can be found in Hendricks and Porter ('89) and Porter ('95). We present here only salient features of the data relevant for my model. A descriptive statistics of the tracts offered for sales are presented below, where bids are in millions of nominal US $\$$.

Table 2: Descriptive Statistics of Tracts Offered for Sale: $1954-1990$

\footnotetext{
${ }^{34}$ I am grateful to Prof. Ken Hendricks and Prof. Joris Pinkse for sharing the data.
} 


\begin{tabular}{ccccc}
\hline \hline Period & \# of Tracts & Tracts Receiving Bids & Bids Per Tract & Sold \\
\hline $1954-1960$ & 950 & 454 & 2.94 & 419 \\
$1961-1967$ & 1460 & 841 & 2.95 & 801 \\
$1968-1974$ & 2041 & 1269 & 4.04 & 1103 \\
$1975-1982$ & 6811 & 2753 & 2.59 & 2383 \\
$1983-1990$ & 136952 & 8011 & 1.38 & 7582 \\
\hline
\end{tabular}

\subsection{Working Data}

Data of oil tracts auctioned between 1954 and 1969 are used for the estimation, since during this period the price of oil was more or less constant and hence can be assumed to not affect bidders' ex-ante profitability expectations. Possibility of joint bidding is not modelled in this paper and was not prevalent fin $1954-69$. Hence, we ignore joint bidding and work with the subset of the data with no joint bidding. The maximum number of bidders in any tract was 18 , the median being 4 . We therefore work only with tracts receiving at most 4 bids. Note that the estimation procedure for drainage auctions have to be carried out for each set of bidders separately. Also, suppose there are 3 bidders in a drainage tract, then there can be 1 strong and 2 weak or 3 symmetric (weak) bidders. The reserve price of oil field tracts were US $\$ 15$ per acre which is much lower than the average bid. Also there is less than $0.25 \%$ of the bids in the interval $[15,20]$. We therefore assume, as in the theoretical model that the reserve price is non-binding. Sometimes the federal government rejected bids above the reserve price too. This accounted for around $2 \%$ of the bids. Hence the random reserve price issue is also ignored. Also we regress, as in Porter ('95), log of tract bids on possible tract specific dummies to analyze possible heterogeneity issue. The F-test rejects the tract heterogeneity when controlled for the number of bidders. Since our econometric methodology is for a given number of bidders we ignore tract heterogeneity issues.

Selected Statistics on wildcat and drainage tracts for 1954-1969 are given below ${ }^{35}$

Table 3 : Summary Statistics on Wildcat and Drainage Tracts: 1954-1969

\begin{tabular}{lcc}
\hline \hline & Wildcat & Drainage \\
\hline Number of Tracts & 1056 & 144 \\
Number of Tracts Drilled & 748 & 124 \\
Number of Productive Tracts & 385 & 86 \\
Average Winning Bid & 2.67 & 5.76 \\
Average Net Profits & 1.22 & 4.63 \\
Average Tract Value & 5.27 & 13.51 \\
Average Number of Bidders & 3.46 & 2.73 \\
\hline
\end{tabular}

The following table describes the major features of the drainage tracts sold for the period ${ }^{36} 1954-69$.

Table 4: Role of Information in Drainage Tracts

\footnotetext{
${ }^{35}$ Source: Hendricks, Porter and Boudreau ('87). Dollar Figures are in millions of 1972 US\$.

${ }^{36}$ Source: Hendricks, Porter and Boudreau ('87). Dollar Figures are in millions of 1972 US\$.
} 


\begin{tabular}{lcc}
\hline \hline & Wins by Neighbor Firms & Wins by Non-Neighbor Firms \\
\hline Number of Tracts & 59 & 55 \\
Number of Tracts Drilled & 47 & 51 \\
Number of Productive Tracts & 36 & 31 \\
Average Winning Bid ('72 US\$m) & 6.04 & 4.87 \\
Average Gross Profits ('72 US\$m) & 12.75 & 4.45 \\
Average Net Profits ('72 US\$m) & 6.71 & -0.42 \\
\hline
\end{tabular}

The gross profit was calculated as the value of oil recovered minus the drilling cost. Net profit was measured as ex post revenue minus the drilling costs minus the bid.

The above tables suggest the following major points:

1) Strong bidder has informational advantage: Both social rents and net profits are much higher on tracts won by a strong bidder. Discounted social value as measured by ex post revenue minus drilling costs was on an average US $\$ 12.75$ million for tracts won by strong bidders and US $\$ 4.45$ million for tracts won by weak bidders.

Net profit measured as ex post revenue minus the drilling costs minus the bid was on an average US\$ 6.71 million for tracts won by strong bidders and only US $\$-0.42$ million for tracts won by weak bidders. This suggests that information however noisy has some role to play in deciding how much to bid for the drainage tracts, and considering the fact that most of the drainage tracts were won by strong bidders, it suggests evidence that the drainage tracts were under priced and reserve prices should be increased.

2) Higher gross profit per acre from drainage tracts than wildcat tracts: Average gross profit per acre measured as ex post revenue minus cost for wildcat tracts was US\$793.7 million and that for drainage tracts was US $\$ 4863.8$ million.

3) Number of Bidders is endogenous: All firms submit bids in less than half of the tracts offered for sale. Thus pre-bidding seismic signals may play a role in determining whether to bid or not.

4) 'Excessive Entry' in wildcat tracts: Out of the wildcat tracts sold oil was found only in $36 \%$ of them whereas in more than $60 \%$ of the cases oil was found in drainage tracts.

\subsection{Reduced Form Prediction}

In this section, we analyze whether the bidders were also taking the potential profitability of the drainage tracts into account while deciding to bid for the wildcat tracts. A researcher only observe the decision to bid and the amount of bid for the wildcat tracts. However the data set also have ex-post informations on tracts' value of oil, drilling cost, acerage of the drainage tracts and whether the tracts were dry or not. Although these ex-post information are also unavailable to the firm while entering and bidding for the wildcat tracts, we use them as a reasonable proxy about bidder's information level.

In the theoretical model it was argued that there will be excessive entry in the wildcat auctions and bidders also bid higher in the wildcat auction depending on the informational advantage he will foresee as a strong bidder over the weak bidder. We take ex-post gross profit of the drainage tracts as a proxy for the 
profitability of the drainage tracts. Below we explore whether these predictions were true at the reduced form level for both entry and bidding stage of the wildcat tracts.

\subsubsection{Entry in Wildcat Auction}

In this section we report evidence of the presence of effects of drainage tracts on the decision to bid for the wildcat tracts controlling for the competition and profitability of wildcat tracts. In the following table we report he estimated elasticity on the basis of the median level based on OLS regression results for entering the wildcat auction (no. of bidders in wildcat: $w n$ ) regressed on the ex-post value of drainage tracts $(D \pi)$ conditional on the ex-post values of wildcat tracts $(w \pi)$. The base equation of regression was

$$
w n=\alpha_{0} \cdot w \pi+\alpha_{1} w \pi^{2}+\alpha_{2} \cdot D \pi+\alpha_{3} \cdot D \pi^{2}
$$

Table 5a: Elasticity Calculation for Entry Based on Median Value

\begin{tabular}{crc}
\hline \hline Independent Variables & Elasticity & Standard Error \\
\hline$w \pi$ & 0.038 & 0.003 \\
$D \pi$ & 0.036 & 0.002 \\
\hline
\end{tabular}

Dependent Variable Number of Bidders

Thus conditional on the wildcat values the entering decision is significantly affected by the value of the drainage tracts. The elasticity is almost same for wildcat and drainage values.

Table 5b: Poisson Regression; Incidence rates on Entry

\begin{tabular}{ccl}
\hline \hline Independent Variables & No of Bidder in Wildcat & Standard Error \\
\hline$w \pi$ & 1.001 & $3.95-06$ \\
$w \pi^{2}$ & 1 & $3.22-11$ \\
$D \pi$ & 1.002 & $3.68-06$ \\
$D \pi^{2}$ & 1.001 & $1.87-11$ \\
\hline
\end{tabular}

Dependent Variable Number of Bidders

Thus, increase in the drainage tract values increases the number of bidders by $0.2 \%$.

\subsubsection{Bidding in Wildcat Auction}

Conditional on entry the estimated elasticity on bidding decision (wbid) based on OLS regression of bidding of wildcat tracts is regressed on ex-post wildcat and drainage values.

$$
w b i d=\alpha_{0} \cdot w \pi+\alpha_{1} w \pi^{2}+\alpha_{2} \cdot D \pi+\alpha_{3} \cdot D \pi^{2}+\alpha_{4} \cdot w n
$$

Table 5c: Elasticity Calculation Based on Median Value 


\begin{tabular}{crr}
\hline \hline Independent Variable & Elasticity & Standard Error \\
\hline$w \pi$ & 0.02 & 0.003 \\
$D \pi$ & 0.01 & 0.003 \\
$w n$ & 0.59 & 0.012 \\
\hline
\end{tabular}

Dependent Variable log of winning bid

Thus all the reduced form variables have expected signs. Although the estimated effects are low, but in general bids are in millions of dollars hence their absolute effects are not small.

\section{Structural Estimation Results}

In this section, we present the structural estimation results. Major structural elements of our model are the distributions of pre-bidding pseudo values of the drainage tracts to the strong and weak bidders and the distribution of pseudo values of the wildcat tracts.

We first report the estimates from the drainage auctions. Let us investigate the interesting case of where there are only two bidders. Note that the fact that there are only two bidders is an indication that bidders perceive the value of the tract is not possibly very high. In this extreme case, even though the weak bidder has a higher pseudo value he shed his bid more against a strong bidder. The structural estimates supports this fact. In figures 3 and 4 we represent the estimated functions of $\widehat{\xi}_{1}$ and $\widehat{\xi}_{0}$ which is the inverse of the equilibrium strategy as given by equations (23) and (24) when there are only two bidders. The estimated densities of $\widehat{v}_{1}$ and $\widehat{v}_{0}$ are depicted in figures 5 . The mean, median and variance of the strong and weak bidders' estimated valuations are reported in the table (all values are in US1982 \$ in millions) below.

Table 6: Summary Statistics of Estimated Valuation

\begin{tabular}{lcc}
\hline \hline & Strong Bidder & Weak Bidder \\
\hline Mean & 1.03 & 1.16 \\
Median & 1.18 & 1.43 \\
3rd Quantile & 1.09 & 1.67 \\
\hline Variance & 0.12 & 0.25 \\
\hline Wins & $0.57 \%$ & $0.43 \%$ \\
\hline
\end{tabular}

Insert Figure $3-6$ About Here

It appears that the density of the strong bidder has less mean median and variance than that of the weak bidders. The smoothed densities of the strong and weak bidders are plotted in figure 5 . It is apparent that the weak bidder's distribution of pseudo values are higher than that of the strong bidder. However the weak bidder won only in $43 \%$ of auctions where there are two bidders. This suggests that the weak bidder sheds his valuations more than the strong bidder and bids timidly. This is consistent with the informational superiority of the strong bidder. The smoothed densities of two bidders are compared in figure 6. A Kolmogorv-Smirnov test and a bootstrap test based on 3000 bootstrap samples cannot reject the hypothesis 
of different distributions of pseudo values for strong and weak bidders. The test statistics are reported in the following table.

Table $6 a$ : Test of Equality of Distributions of Pseudo Values

\begin{tabular}{cc}
\hline \hline Null Hypothesis : Strong and Weak bidder's Distributions are Equal & $p-$ value \\
\hline Kolmogorov- Smirnov Test & 0.02 \\
Bootstrap Test ( Sample size 3000) & 0.03 \\
\hline
\end{tabular}

The bootstrap confidence band and the densities are depicted in figure 5. It appears that although the strong bidder had lower pseudo values, the density of the strong bidder was more concentrated than that of the weak bidder. This may suggest that the strong bidder had a more informative signal. The picture and the statistical test depicted above only says that the distributions of the strong and weak bidders are different. A formal test of whether the strong bidder was more informed or not is given in next section.

The estimated densities of the strong and weak bidders when there were one strong and two weak bidders are given in figure 6. A bootstrap test also cannot accept the hypothesis whether the densities are equal $(p-$ value $=0.00)$. The results are reported below. However as the graph suggests, there is no conclusive evidence that either of the bidder's pseudo values were higher.

Table $6 b$ : Test of Equality of Distributions of Pseudo Values

\begin{tabular}{cc}
\hline \hline Null Hypothesis : Strong and First Weak bidder's Distributions are Equal & $p-$ value \\
\hline Kolmogorov- Smirnov Test & 0.03 \\
Bootstrap Test ( Sample size 3000) & 0.04 \\
\hline
\end{tabular}

In figures 6 we depict $\widehat{U}$ as estimated by equation (15) which also takes into account the possible dynamics. The estimated density of $\widehat{U}$ is represented in figure 7 .

Insert Figure $7-8$ About Here

An important measure of the mark-up is given by the winner's informational rent as measured by $\frac{\widehat{v}-b}{\hat{v}}$, where $\widehat{v}$ is the estimated pseudo values. We report below the winner's informational rents for drainage and wildcat auctions in the following table.

Table $7 a$ : Summary Statistics of Winner's Informational Rent

\begin{tabular}{lccc}
\hline \hline \multicolumn{1}{c}{ Auction Type } & Mean & Median & 3rd Quantile \\
\hline Wildcat Auction (no Dynamics) & 0.65 & 0.7 & 0.81 \\
Wildcat Auction (with Dynamics) & 0.54 & 0.59 & 0.7 \\
Drainage Auction: Strong Bidder & 0.71 & 0.77 & 0.87 \\
Drainage Auction: Weak Bidder & 0.63 & 0.62 & 0.73 \\
\hline
\end{tabular}

Thus on an average the winner's informational rent is $77 \%$ for strong bidders and $62 \%$ for weak bidders in the drainage auctions. Thus on an average the government is capturing only $38 \%$ from the weak bidders 
willingness to pay and $23 \%$ from the strong bidder's willingness to pay. These numbers are consistent but slightly different and higher from the analysis of Campo, Perrigne Vuong('03) where they analyzed asymmetry originating due to the presence of joint bidding. As evident from the theoretical analysis, our model of asymmetry is different from theirs. The informational rent in the wildcat auctions are quite high too. In the wildcat auctions, the bidders are willing to pay $10 \%$ more to take possible future informational advantage.

Table $7 b$ : Value of Information

\begin{tabular}{ll}
\hline \hline Drainage Auction Type & Value of Information* \\
\hline Asymmetric Interdependent Value & $12 \%$ (upper bound) \\
Asymmetric Private Value & $10 \%$ (exact) \\
\hline
\end{tabular}

*: As a percentage of wildcat informational rent

This is the value of information bidders perceive about the drainage tract while bidding for the wildcat tract.

There are several possible limitations. For example, we ignored the issue of joint bidding and only analyzed the cases for which there were no joint bidding for our sample. Joint bidding although very low for the sample period of the data used ${ }^{37}$, the absence of joint bidding, however, could be an equilibrium phenomenon. Allowing for joint bidding, in a dynamic setting, would complicate the analysis by introducing dynamic information sharing, punishments etc.

Table 7c: Entry Parameters

\begin{tabular}{|c|c|c|}
\hline Drainage Auction Type & Values & Bootstrap Standard Errors \\
\hline Sunk Cost of Estimation $K$ & & \\
\hline Value of the wildcat tract with only one bidder: $U_{0}$ & & \\
\hline
\end{tabular}

\section{Semi-parametric Test of Asymmetry}

A major assumption of our model is that bidders in the drainage auctions can be divided into two categories: strong and weak. A strong bidder is the bidder who receives a 'better' signal of the value of oil stored relative to the weak bidder. Note that this assumption was not imposed while estimating the distributions of equilibrium ex ante values. It was only assumed that both bidders receive private signals and they are asymmetric. We present below a semi-parametric test of the assumption that strong bidder knows more about his ex post valuation while bidding based on copula methods. More details and a general estimation procedure for first price auctions using copulas can be found in Gupta ${ }^{38}$ ('04). The basic idea of the test is as follows: We estimate the 'pseudo values' for different bidders $\widehat{v}_{1}^{d}$ and $\widehat{v}_{0}^{d}$, for the interdependent value drainage auction model. We also have ex-post value of oil using the production and drilling cost data $\widehat{V}_{1}^{d}$ and $\widehat{V}_{0}^{d}$ for the strong and weak bidder respectively. Let the underlying joint distribution of the values with the signals be $F_{1}\left(v_{1}^{d}, V_{1}\right)$ and $F_{0}\left(v_{0}^{d}, V_{0}\right)$ for the strong and weak bidders respectively. A simple test of

\footnotetext{
${ }^{37}$ Joint bidding was very low and affected only less than $20 \%$ of the data for the sample period.

${ }^{38}$ see "Copula as a Measure of Affiliation: A Semiparametric Estimation of First Price Auctions", Gupta(04).
} 
'strongness' would be that strong bidder's ex-ante signal $v_{1}$ is more 'affiliated' with ex-post realization $V_{1}$ relative to that of the weak bidder's $v_{0}$ with $V_{0}$. One test can be a test of simple correlation, however correlation is only a linear concept and may not capture the possible non-linearity of the relations. We present below a new test procedure using copula methods.

\subsection{Copulas}

In this section, we briefly review the concept of copula originated in the statistics literature. The word 'copula' came from the word couple. Copulas are functions that 'couples' or joins multivariate distribution function to their one dimensional marginal distribution functions in such a way that it captures the entire dependence structure in the multivariate distribution.

Let $X$ and $Y$ be two random variables with joint distribution $F(X, Y)$ and continuous marginal distribution functions $F_{X}$ and $F_{Y}$ respectively. Then according to Sklar's theorem there exists a unique copula function $C\left(v_{1}, v_{2}\right)$ such that $C\left(v_{1}, v_{2}\right)=F\left(F_{X}^{-1}\left(v_{1}\right), F_{Y}^{-1}\left(v_{2}\right)\right)$ that connects $F(X, Y)$ to $F_{X}$ and $F_{Y}$ respectively. More discussion and specific examples on copulas can be found in Joe ('97) and Nelson ('99). It is easy to see that copula is a map from $[0,1]^{n}$ to $[0,1]$. $C$ can be parametrized by a parameter $\alpha$, to have a specific functional form and be denoted by $C\left(v_{1}, v_{2} ; \alpha\right)$. The most simple copula is the independent copula, given by $C\left(v_{1}, v_{2}\right)=v_{1} v_{2}$. Thus if bidders' ex-ante valuations are independent then the probability that strong and weak bidder's ex-ante valuations are below their $50^{t h}$ percentile be given by, $C\left(v_{1}, v_{0}\right)=0.5 \times 0.5=0.25$. A popular measure of dependence is simple correlation which may fail to capture the inherent non-linearity in the relationship. For example, we reproduce the figures from Embrechts et al in figure 9 where they have shown two entirely different dependence structures can have the same correlation. Copula on the other hand captures the inherent non-linear dependence structure.

Gaussian copula, Frank copula, Gumbel copula, Clayton copula are examples of parametric families of copulas $^{39}$. The parameter $\alpha$ measures the degree of dependence between the random variables $v_{1}$ and $v_{2}$. The copula parameter can also be interpreted as a measure of affiliation as shown in Gupta ('04). A semiparametric procedure to estimate first price auction model and their statistical properties are derived in that paper.

Now by definition copula is a unique distribution function $C_{1}\left(F_{1}\left(s_{1}^{d}\right), F_{V}\left(V_{1}\right), \alpha_{1}\right)$ such that $F_{1}\left(s_{1}^{d}, V\right)$ $=C_{1}\left(F_{1}\left(v_{1}^{d}\right), F_{V}\left(V_{1}\right), \alpha_{1}\right)$, similarly $C_{0}\left(F_{0}\left(v_{0}^{d}\right), F_{V}\left(V_{0}\right), \alpha_{0}\right)=F_{0}\left(v_{0}^{d}, V_{0}\right)$, where $\alpha_{1}$ is the copula parameters measuring the dependence (concordance) between $v_{1}^{d}$ and $V_{1}, \alpha_{0}$ is defined similarly. A test that $s_{1}^{d}$ is more related with $V_{1}$ than relative to $v_{0}^{d}$ with $V_{0}$ would be equivalent to test that $\alpha_{1}>\alpha_{0}$. To test this we need to estimate $\alpha^{\prime} s$. Estimation of $\alpha$ follows the following two step simple procedure.

Step 1: Estimate the marginal distribution of $\widehat{v}_{i}^{d}, i \in\{1,0\}$ and that of $\widehat{V}_{i}$ non-parametrically.

Step 2: Using the estimated $\widehat{v}_{0}$, and $\widehat{v}_{1}$, estimate the copula ${ }^{40}$ parameter $\alpha_{i}$ by maximizing the likelihood function

$$
\max _{\alpha} L(\alpha)=\sum_{k=1}^{T} \log \left[c\left\{\widehat{F}_{i}\left(\widehat{v}_{i}\right), \widehat{F}_{V}\left(\widehat{V}_{i}\right), \alpha\right\}\right], \quad i=\{1,2\}
$$

\footnotetext{
${ }^{39}$ Some details about the properties of copulas are given in the appendix.

${ }^{40}$ There are many well known copula functions to chose from, like Frank copula, Clayton copula, Gumbel copula etc.
} 
We present below preliminary results of such a test for drainage auctions where only two bidders were present using Frank copula, given as

$$
C\left(v_{1}, v_{2}\right)=\log _{\alpha}\left[1+\frac{\left(\alpha^{v_{1}}-1\right)\left(\alpha^{v_{2}}-1\right)}{(\alpha-1)}\right]
$$

with an associated density function

$$
\begin{aligned}
c\left(v_{1}, v_{2}\right) & =\log \left(\alpha^{-1}\right) \frac{\alpha^{v_{1}} \alpha^{v_{2}}}{1-\alpha}\left[1-\frac{\left(1-\alpha^{v_{1}}\right)\left(1-\alpha^{v_{2}}\right)}{(1-\alpha)}\right]^{-2}, \text { if } \alpha>0, \alpha \neq 1 \\
& =1 \text { if } \alpha=1
\end{aligned}
$$

We report the estimates, bootstrap standard errors and confidence intervals below.

Table 8 : Test of Asymmetry Based on Copula

\begin{tabular}{lcccc}
\hline \hline Copula & $\alpha_{i}$ & Bootstrap $t$-statistic & Bootstrap Standard Error & $95 \%$ Confidence Interval \\
\hline Strong Bidder & 0.84 & 14 & .06 & {$[.63, .95]$} \\
Weak Bidder & 0.69 & 7.6 & .09 & {$[.55, .81]$} \\
\hline
\end{tabular}

Both the strong and weak bidders' ex-ante pseudo values are significantly related to their ex-post values. This supports the assumption that both bidders' signals are related to their ex-post valuation. Based on the bootstrap $t$ - statistic of 1.65, we also cannot reject the hypothesis that strong bidder's ex-ante pseudo value is better associated to its ex-post values relative to the weak bidder.

Copula is a more general measure of dependences between two random variables than simple correlation, which measures only linear association. There is a unique mapping between copulas and the rank correlation measure Kendall's $\tau$, which measures whether the pairs of two random variables are concordant or discordant. For a more detailed discussion and some useful properties of copulas see the appendix.

\section{Counterfactual Experiments of Choosing Different Mechanisms}

In this section we perform counterfactual policy experiment of adopting different selling mechanisms and compare government's revenue. we have estimated the distributions of ex-ante valuations of bidders in wildcat and drainage auctions. We use them to compute the bidding strategies under different selling strategies. We do not know what the optimal mechanism is in selling such kind of auctions. In the following subsections we only explore what revenues some other popular mechanisms would have yielded.

\subsection{Experiment 1: Asymmetric Drainage Auctions}

Note that the we know that bidders in drainage auctions are asymmetric in terms of their level of information. In previous section we used copula methods to quantify the degree of asymmetry in terms of the copula parameters. The weak bidder is obviously in a disadvantageous position, which is common knowledge before bidding and this may reduce competition. There are many mechanisms proposed in the theoretical literature to promote competition in such an environment. One such is called bidding credits. In such mechanisms 
weak bidder must pay only a fraction of his bids if he wins. Now what fractions should be a pertinent question. We use the degree of asymmetry measured as the copula parameters as the fraction. Hence here are the mechanisms: Let $\alpha=\frac{\alpha_{0}}{\alpha_{1}}$ be the degree of asymmetry where $\alpha_{1}$ is the degree of association of strong bidder's ex-ante and ex-post valuations and $\alpha_{0}$ be the same for the weak bidder: arguably $\alpha<1$, we consider the following two mechanisms of bidding credits.

Mechanism 1 : Strong bidder bids $b_{1}$, weak bidder bids $b_{0}$;

If $b_{1}>\frac{1}{\alpha} b_{0} \Rightarrow$ Strong bidder wins and pays $b_{1}$ else weak bidder wins and pays $b_{0}$.

Mechanism 2: Strong bidder bids $b_{1}$, weak bidder bids $b_{0}$;

If $b_{1}>b_{0} \Rightarrow$ Strong bidder wins and pays $b_{1}$ else weak bidder wins and pays $\alpha b_{0}$.

Mechanism 3: Strong bidder bids $b_{1}$, weak bidder bids $b_{0}$;

If $b_{1}>\frac{1}{\alpha} b_{0} \Rightarrow$ Strong bidder wins and pays $b_{1}$ else weak bidder wins and pays $\alpha b_{0}$.

It is easy to see that the equilibrium bidding strategies under two mechanisms are given by,

Table 9 : Counterfactual Experiments: Equilibrium Strategies

\begin{tabular}{cll}
\hline \hline Mechanisms & Strong Bidder & Weak Bidder \\
\hline Mechanism 1 & $b_{1}=v_{1}-\frac{1}{\alpha} \times h a z_{1 ; \alpha}$ & $b_{0}=v_{0}-\alpha \times h a z_{0 ; \alpha}$ \\
Mechanism 2 & $b_{1}=v_{1}-h a z_{1}$ & $b_{0}=\frac{1}{\alpha} \times\left(v_{0}-\alpha \times h a z_{0}\right)$ \\
Mechanism 3 & $b_{1}=v_{1}-\frac{1}{\alpha} h a z_{1 ; \alpha}$ & $b_{0}=\frac{1}{\alpha} \times\left(v_{0}-\alpha \times h a z_{0 ; \alpha}\right)$ \\
\hline
\end{tabular}

where $h a z_{i ; \alpha}$ is the inverse of the hazard of bid distribution faced by the $i^{\text {th }}$ bidder when bidder 1 bids $b_{1}$ and bidder 0 bids $\alpha b_{0}$. haz $z_{i}$ is inverse of the hazard of bid distribution faced by the $i^{\text {th }}$ bidder when bidder 1 bids $b_{1}$ and bidder 0 bids $b_{0}$. This counterfactual experiment led to the weak bidder winning more of the auctions and also generating approximately 5 times more revenue than the current format. Below we present the summary statistics of winner's informational rent for these mechanisms.

Table 10 : Comparisons of Informational Rents in Counterfactual Experiments

\begin{tabular}{ccccccccc}
\hline \hline \multirow{2}{*}{ Mechanisms } & \multicolumn{3}{c}{ Strong Bidder } & & \multicolumn{3}{c}{ Weak Bidder } \\
& 1stQ & Median & 3rdQ & & 1stQ & Median & 3rdQ \\
\hline Mechanism 1 & 0.62 & 0.77 & 0.84 & & 0.62 & $0 . .60$ & 0.85 \\
Mechanism 2 & 0.71 & 0.78 & 0.86 & & 0.59 & 0.66 & 0.77 \\
Mechanism 3 & 0.61 & 0.75 & 0.82 & & 0.64 & 0.73 & 0.77 \\
Auction Format & 0.71 & 0.78 & 0.86 & & 0.54 & 0.63 & 0.75 \\
\hline
\end{tabular}

Note that the informational rents go down for strong bidders and it is higher for the weak bidder. Also the weak bidder is winning more auctions.

The above analysis only considers the drainage auctions and ignores the impact of drainage sales mechanism on wildcat auctions. Intuitively if a wildcat bidder knows that he is going to be treated differently in drainage auctions depending on whether he is strong or weak, the option value of being a strong bidder may go down. This would lead to reduction of the overbidding and excessive entry component in the wildcat 
sales. We consider the impact of different selling strategies of drainage tracts on wildcat bidding behaviors below.

\subsection{Impact of Asymmetric Drainage Auction on Wildcat Bidding}

Asymmetric Drainage auction like bidding credit as described above is aimed at giving the weak bidder some advantage and reduce the degree of asymmetry. This reduces the advantage of being a strong bidder and the attractiveness of being a strong goes down relatively. Looking at the equilibrium bidding equation in 12 this reduces the future rent or the value of information by reducing the gap between the strong and weak bidder's expected profits from drainage auction. This in turn reduces the overbidding amount in the wildcat tracts. Thus although government's revenue goes up in the drainage auction, it goes down in the wildcat bidding and the overall impact on government's revenue depends on the relative strengths of the two. We present below the impact of asymmetric drainage bidding on wildcat bidding.

Table 11 : Impact of Asymmetric Drainage Auction on Wildcat Bidding

\begin{tabular}{lc}
\hline \hline Mechanisms & Winner's Informational Rent \\
\hline Mechanism 1 & 0.61 \\
Mechanism 2 & 0.66 \\
Mechanism 3 & 0.67 \\
Current Auction Format & 0.59 \\
\hline
\end{tabular}

However the overall impact was still positive and preliminary numbers suggests that the overall revenue of the government could go up by about $30 \%$ more if they had followed the asymmetric drainage auction. Note that this computation depends crucially by estimating the degree of asymmetry. A higher (lower) $\alpha$ may increase (decrease) the overall revenue via its impact on the value of information in the wildcat bidding.

\section{Conclusion and Ongoing Work}

In this paper, we have formulated and estimated a dynamic auction model where toehold informational asymmetry is endogenous. The winner from the symmetric bidders in the first period auction gains superior informational toehold for the second period auction, making the second period a contest among asymmetric bidders. This makes the toehold asymmetry for the second unit endogenous and the first unit more valuable reflecting the option value of having more information for the second unit. Bidders therefore overbid for the first unit for this option value. We separately identified the premium paid for this option value of this information from the willingness to pay for the first unit. We structurally estimated the unobserved distribution of valuations for both the auctions, the degree of informational asymmetry and the option value of acquiring costly information. We used copula techniques from statistics literature to quantify and semiparametrically test the degree of asymmetry amongst bidders. Finally we conduct counterfactual experiment to find better selling strategies.

We apply this model to data from OCS oil tract auctions, where the first period (wildcat tract auction) winner has better information about the tract being sold next period (drainage tract auction) and becomes a 
strong bidder. The possibility of future asymmetry affects bidders' bidding behavior in the first period. We estimate this dynamic model using a two step procedure. The estimates indicate that the federal government is only recovering $23 \%$ of the 'strong' buyers' willingness to pay in the drainage sales. In the wildcat sales, we find that the bidders are willing to pay up to $12 \%$ more as an option premium to account for possible future informational advantage. The estimates also suggest that weak bidders bid timidly despite having stochastically higher pseudo values and hence win less, which is consistent with the theory and indicates the presence of winner's curse. We use these estimated unobserved ex-ante valuations to conduct counterfactual experiments of different selling strategies for selling such goods and compare the government's revenue.

We cannot reject the hypothesis that strong bidder in drainage auctions knows 'more' about his ex-post valuation than the weak bidder. As a first paper, we quantify this degree of asymmetry as a structural element of the model and found that the strong bidder knows $18 \%$ more than the weak bidder. The estimated marginal valuations are then used to first time conduct counterfactual experiment of alternate selling strategies in asymmetric drainage auctions. Since bidders are asymmetric, an asymmetric auction may yield higher revenue. We use the estimated degree of asymmetry to treat strong and weak bidders and compare three alternate mechanisms of 'bidding credits' where weak bidder is given some advantage in bidding according to this degree of asymmetry. The results suggests that the government could have earned on an average 2 times more in drainage auctions following these mechanisms. Asymmetric treatments of bidders in drainage auctions should affect the bidding behavior in wildcat auctions too as being a strong bidder may not be as attractive as before. When the asymmetric drainage auctions are taken into account in the bidding behavior in wildcat auctions the total revenue earned goes down but is still higher than the current mechanism. Tthe empirical methodology developed in this paper is easily applicable to analyze many other hitherto unexplored dynamic auction settings like defence procurements, optimal toeholds and takeovers etc. where informational asymmetry is endogenous.

\section{Appendix}

\subsection{Proofs of the Theoretical Model}

Proof. of Lemma 1 :First note that the utility function has the single crossing property and affiliation of signals guarantees that the distribution of valuations is log-supermodular and we assume that the assumptions required by McAdams('04) are satisfied for a pure strategy equilibrium to exist. Note that, bidder $i$ solves the following problem,

$$
T_{i}(D)=\max _{b_{i}^{d} \geq 0}\left\{\left(v_{i}\left(s_{i}^{d}, s_{j}^{d}\right)-b_{i}^{d}\right) \times \operatorname{Pr}\left(b_{j}\left(s_{j}^{d}\right)<b_{i}\left(s_{i}^{d}\right)\right), i, j=\{0,1\}, i \neq j\right.
$$

setting inverse of $b_{i}^{d}\left(s_{i}\right)$ to $\phi_{i}\left(b_{i}^{d}\right)$,

$$
\begin{gathered}
T_{i}(D)=\max _{b_{i}^{d} \geq 0}\left\{\left(v_{i}\left(s_{i}^{d}, s_{j}^{d}\right)-b_{i}^{d}\right) \times \operatorname{Pr}\left(\phi_{j}\left(b_{j}^{d}\right)<\phi_{j}\left(b_{i}^{d}\left(s_{i}^{d}\right)\right), i, j=\{0,1\}, i \neq j\right.\right. \\
T_{i}(D)=\max _{b_{i}^{d} \geq 0}\left\{\left(v_{i}\left(s_{i}, s_{j}\right)-b_{i}^{d}\right) \times F_{j}\left(s_{j}<\phi_{j}\left(b_{i}^{d}\left(s_{i}^{d}\right)\right), i, j=\{0,1\}, i \neq j\right.\right.
\end{gathered}
$$


Taking logarithm and differentiating with respect to $b_{i}^{d}$, and since in equilibrium it is optimal to set $v_{i}\left(s_{i}, s_{j}\right)=v_{i}\left(s_{i}, \phi_{j}\left(b_{i}^{d}\left(s_{i}^{d}\right)\right)=v_{i}\left(s_{i}, \theta_{i}\left(s_{i}^{d}\right)\right)\right.$, where $\theta_{i}\left(s_{i}^{d}\right)=\phi_{j}\left(b_{i}^{d}\left(s_{i}^{d}\right)\right.$ is a monotonic function of $s_{i}^{d}$ : we get the first order conditions,

Similarly,

$$
\frac{F_{0}^{\prime}}{F_{0}} \phi_{0}^{\prime}\left(b_{1}^{d}\right)=\frac{1}{v_{1}\left(s_{1}, \theta_{1}\left(s_{1}^{d}\right)\right)-b_{1}^{d}}
$$

$$
\frac{F_{1}^{\prime}}{F_{1}} \phi_{1}^{\prime}\left(b_{0}^{d}\right)=\frac{1}{v_{0}\left(\theta_{0}\left(s_{0}^{d}\right), s_{0}\right)-b_{0}^{d}}
$$

satisfying the relevant boundary conditions as described below. Hence the proof of the lemma.

Proof. of Lemma 2 Suppose bidder $i$ decides to bids for the wildcat auction, in the simple case of two bidders he is solving the following

$$
\begin{aligned}
Q_{1 ; i}\left(s_{i}^{w}\right)= & \max _{b_{i}^{w} \geq 0}\left[\left\{\operatorname { P r } ( \alpha _ { - i } = 1 | s _ { i } ^ { w } ) \left\{\left(U\left(s_{i}^{w}, \widetilde{s}_{i}^{w}\right)-b_{i}^{w}\right) \times \operatorname{Pr}\left(b_{-i}^{w}<b_{i}^{w} \mid s_{i}^{w}\right)-K\right.\right.\right. \\
& \left.+\beta \sum_{j=1}^{2} \operatorname{Pr}\left(j \operatorname{wins} W_{A}\right) \int T_{i}(D) d F\left(s^{d}, D\right)\right\} \\
& \left.+\operatorname{Pr}\left(\alpha_{-i}=0 \mid s_{i}^{w}\right)\left\{\left(U_{0}\left(s_{i}^{w}\right)-b_{i}^{w}\right)+\beta \int T_{i}(1) d F\left(s^{d}, D=1\right)\right\}\right]
\end{aligned}
$$

where $T\left(X^{\prime}, 1\right.$ is strong), $T\left(X^{\prime}, 1\right.$ is weak) are as defined before. Equivalently, using the definitions of $M_{Y^{w} \mid s^{w}}=\operatorname{Pr}\left(\alpha_{-i}=1 \mid s_{i}^{w}\right) F^{w}\left(\phi\left(b_{i}^{w}\right)\right)$, and differentiating with respect to $b_{i}^{w}$ we get the first order condition,

$$
\begin{gathered}
\left\{\left(U-b_{i}^{w}\right) \frac{m_{Y_{w} \mid s_{w i}}\left(s_{1}^{w} \mid s_{1}^{w}\right)}{b^{\prime}\left(s_{w}\right)}-M_{Y_{w i} \mid s_{i}}\left(s_{1}^{w} \mid s_{1}^{w}\right)+\beta \frac{m_{Y_{w} \mid s_{w i}}\left(s_{1}^{w} \mid s_{1}^{w}\right)}{b^{\prime}\left(s_{w}\right)}\left[\int T(D=1) d F\left(s^{d}, D=1\right)\right]\right. \\
\left.-\beta\left[\frac{m_{Y_{w} \mid s_{w}}\left(s_{1}^{w} \mid s_{1}^{w}\right)}{b^{\prime}\left(s_{w}\right)}\right]\left[\int T(D=0) d F\left(s^{d}, D=0\right)\right]\right\}-\operatorname{Pr}\left(\alpha_{-i}=0 \mid s_{i}^{w}\right)=0
\end{gathered}
$$

with the terminal condition, $b_{W}\left(s^{w^{*}}\right)=0$.Equivalently,

$$
\begin{gathered}
\left(U-b_{i}^{w}\right) \frac{m_{Y_{w} \mid s_{w}}\left(s_{1}^{w} \mid s_{1}^{w}\right)}{b^{\prime}\left(s_{1}^{w}\right)}-M_{Y_{w} \mid s_{w i}}\left(s_{1}^{w} \mid s_{1}^{w}\right)+\beta\left[\frac{m_{Y_{w} \mid s_{w}}\left(s_{1}^{w} \mid s_{1}^{w}\right)}{b^{\prime}\left(s_{1}^{w}\right)}\right] \int\left[T(D=1)-T(D=0] d F\left(s^{d}, D\right)\right. \\
=\left\{\left(U-b_{i}^{w}\right)+\beta \int[T(D=1)-T(D=0)] d F\left(s^{d}, D\right)\right\} \frac{m_{Y_{w} \mid s_{w}}\left(s_{1}^{w} \mid s_{1}^{w}\right)}{b^{\prime}\left(s_{1}^{w}\right)} \\
-M_{w} \mid s_{i}\left(s_{1}^{w} \mid s_{1}^{w}\right)-\operatorname{Pr}\left(\alpha_{-i}=0 \mid s_{i}^{w}\right)=0
\end{gathered}
$$

Equivalently,

$$
\begin{aligned}
\left\{\left(U-b_{i}^{w}\right)+\beta \int\right. & {\left.[T(D=1)-T(D=0)] d F\left(s^{d}, D\right)\right\} \frac{m_{Y_{w} \mid s_{w}}\left(s_{1}^{w} \mid s_{1}^{w}\right)}{b_{w}^{w}\left(s_{1}^{w}\right)} } \\
& -M_{Y_{w} \mid s_{w}}\left(s_{1}^{w} \mid s_{1}^{w}\right)-\operatorname{Pr}\left(\alpha_{-i}=0 \mid s_{i}^{w}\right)=0
\end{aligned}
$$

Note that, under the assumption of monotonic bidding strategies, we expressed the bid distribution function,

$$
G_{B_{w} \mid b_{i}^{w}}^{w}\left(y \mid b_{i}^{w}\right)=M_{Y_{w} \mid s_{w}}\left(\phi\left(B_{w}\right) \mid \phi\left(b_{i}^{w}\right)\right)+\operatorname{Pr}\left(\alpha_{-i}=0 \mid \phi\left(b_{i}^{w}\right)\right)
$$

with the density function,

$$
\begin{gathered}
g_{B_{w} \mid b_{i}^{w}}^{w}=\frac{\operatorname{Pr}\left(\alpha_{-i}=2 \mid s_{1}^{w}\right) F^{w^{\prime}}\left(s_{1}^{w} \mid s_{1}^{w}\right)}{b^{\prime}\left(s_{1}^{w}\right)} \\
=\frac{m(.)}{b^{\prime}\left(s_{1}^{w}\right)}
\end{gathered}
$$

Substituting in the first order conditions, we get,

$$
b_{i}^{w}=U-\frac{G_{B_{w} \mid b_{i}^{w}}^{w}\left(b_{i}^{w} \mid b_{i}^{w}\right)}{g_{B_{w} \mid b_{i}^{w}}^{w}\left(b_{i}^{w} \mid b_{i}^{w}\right)}+\beta \int[T(1 \text { is strong })-T(1 \text { is weak })] d F\left(s^{d}, D\right)
$$




\subsection{Derivation of Equilibrium Equations in Drainage Auctions}

Proof. of 3 Each of 'strong' bidders receives a private signal ${ }^{41} s_{1 i}^{d}$ about his unknown valuation $v_{1}^{d}$ and chooses $b_{1 i}^{d}$ to maximize $E\left[\left(v_{1 i}-b_{1 i}^{d}\right) I\left(B_{-i}^{d} \leq b_{1 i}^{d}\right) \mid s_{1 i}\right]$, where $B_{-i}^{d}$ is the maximum of his rivals' bid. $B_{-i}^{d}=$ $\max _{i}\left\{b_{0 i}^{d}\left(s_{0 i}\right)\right\}$, and $y_{0 i}^{d}=\max _{j} s_{0 j}^{d}$. and $b_{1 i}^{d}($.$) and b_{0 i}^{d}($.$) are the equilibrium strategies of 'strong' and 'weak'$ bidders respectively. We restrict our attention to symmetric, strictly increasing and differentiable equilibrium strategies ${ }^{42}$. By 'symmetry' we mean symmetry within each sub-group of strong and weak bidders. The problem of a 'weak' bidder is thus

$$
\begin{gathered}
\max _{b_{1 i}^{d}}\left(v_{0 i}^{d}\left(s_{1 i}^{d}, y_{0 i}, s_{0 i}^{d}\right)-b_{0 i}^{d}\right) \operatorname{Pr}\left(y_{1 i} \leq \phi_{1}^{d}\left(b_{0 i}^{d}\right) \text { and } y_{0 i} \leq \phi_{0}^{d}\left(b_{0 i}^{d}\right) \mid s_{0 i}^{d}\right) \\
=\max _{b_{1 i}^{d}}\left(v_{0 i}^{d}-b_{0 i}^{d}\right) F_{y_{1}^{*}, y_{0} \mid s_{0}}\left(y_{1 i} \leq \phi_{1}^{d}(.), y_{0 i} \leq \phi_{0}^{d}(.) \mid s_{0 i}^{d}\right)
\end{gathered}
$$

The equilibrium conditions are given below for the common support of signals. Differentiating with respect to $b_{0 i}^{d}$, we get the first order differential equation,

$$
\begin{aligned}
& -F_{y_{1}, y_{0} \mid s_{0}}\left(\phi_{1}^{d}\left(b_{0 i}^{d}\right), \phi_{0}^{d}\left(b_{0}^{d}\right) \mid s_{0 i}^{d}\right)+\left(v_{0 i}^{d}(.)-b_{0 i}^{d}\right)\left[\frac{\partial F_{y_{1}, y_{0} \mid s_{1}}\left(\phi_{1}^{d}\left(b_{i i}^{d}\right), \phi_{0}^{d}\left(b_{0 i}^{d}\right) \mid s_{1 i}^{d}\right)}{\partial y_{1}} \times \frac{1}{b_{1}^{d \prime}\left(\phi_{1}\left(b_{0 i}\right)\right)}\right. \\
& \left.+\frac{\partial F_{y_{1}, y_{0} \mid s_{0}}\left(\phi_{1}^{d}\left(b_{0 i}^{d}\right), \phi_{0}^{d}\left(b_{0}^{d}\right) \mid s_{0 i}^{d}\right)}{\left.\partial y_{0}\right)} \times \frac{1}{b_{0}^{d \prime}\left(\phi_{0}\left(b_{0 i}\right)\right)}\right]=0
\end{aligned}
$$

where $\phi_{1}^{d}($.$) and \phi_{0}^{d}($.$) are the inverse of the equilibrium strategy b^{d}$. Similarly, differentiating with respect to $b_{1 i}^{d}$, we get the first order differential equation for the strong bidder,

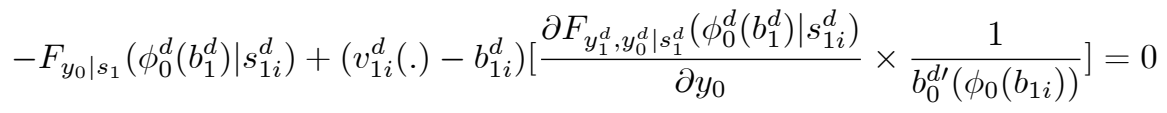

for all $s_{0 i} \in\left[\underline{s}^{d}, \bar{s}^{d}\right]$, where $b_{0 i}^{d}=b_{0 i}^{d}\left(s_{0 i}^{d}\right)$, with the boundary conditions $\underline{b}_{0}^{d}\left(\underline{s}_{0}^{d}\right)=\underline{b}_{1}^{d}\left(\underline{s}_{1}^{d}\right)=0$. To establish identification of distribution of private signals we need to uniquely express the distribution of observed bids in terms of the distribution of signals assuming that the bidders follow equilibrium strategies. Let $B_{1}^{*}=b_{1}$, and $B_{0}^{*}=\max _{i} b_{0 i}$, observe that the conditional distribution of bids are given by

$$
\begin{aligned}
G_{B_{1}^{d}, B_{0}^{d} \mid b_{0}^{d}}(X, X \mid x) & =\operatorname{Pr}\left(B_{1}^{d} \leq X, B_{0} \leq X \mid b_{0}^{d}=x\right) \\
& =\operatorname{Pr}\left(y_{1}^{d} \leq \phi_{1}^{d}(X), y_{0}^{d} \leq \phi_{0}^{d}(X) \mid s_{0}^{d}=\phi_{0}^{d}(x)\right) \\
& =F_{y_{1}, y_{0} \mid s_{0}}\left(\phi_{1}^{d}(X), \phi_{0}^{d}(X) \mid \phi_{0 i}^{d}(x)\right)
\end{aligned}
$$

Differentiating we get,

$$
\begin{gathered}
\frac{d G_{B_{1}^{d}, B_{0}^{d} \mid b_{0}^{d}}(X, X \mid x)}{d X}=\frac{\partial F_{y_{1}, y_{0} \mid s_{0}}\left(\phi_{1}^{d}(X), \phi_{0}^{d}(X) \mid \phi_{0 i}^{d}(x)\right)}{\partial y_{1}^{d}} \times \frac{1}{b_{1}^{d^{\prime}}\left(\phi_{1}^{d}(X)\right)} \\
+\frac{\partial F_{y_{1}, y_{0} \mid s_{0}}\left(\phi_{1}^{d}(X), \phi_{0}^{d}(X) \mid \phi_{1 i}^{d}(x)\right)}{\partial y_{0}^{d}} \times \frac{1}{b_{0}^{d^{\prime}}\left(\phi_{0}^{d}(X)\right)}
\end{gathered}
$$

Using the above the first order conditions for the weak bidders can be rewritten as

$$
v_{0}^{d}\left(s_{0 i}^{d}, s_{0 i}^{d}, s_{0 i}^{d}\right)=b_{0}^{d}+\frac{G_{B_{1}^{d}, B_{0}^{d} \mid b_{1}^{d}}\left(b_{0}^{d}, b_{0}^{d} \mid b_{0}^{d}\right)}{d G_{B_{1}^{d}, B_{0}^{d} \mid b_{1}^{d}}\left(b_{0}^{d}, b_{0}^{d} \mid b_{0}^{d}\right) / d X}=\xi_{0}^{d}\left(b_{0}^{d}, G\right)
$$

Similarly for the strong bidders,

$$
v_{1}^{d}\left(s_{1 i}^{d}, y_{0 i}^{d}=s_{1}^{d}\right)=b_{1}^{d}+\frac{G_{B_{0}^{d} \mid b_{1}^{d}}\left(b_{1}^{d} \mid b_{1}^{d}\right)}{d G_{B_{0}^{d} \mid b_{1}^{d}}\left(b_{1}^{d} \mid b_{1}^{d}\right) / d X}=\xi_{1}^{d}\left(b_{1}^{d}, G\right)
$$

\footnotetext{
${ }^{41}$ Note that, the signals are affiliated and hence so are $s_{i k}^{d}, y_{k i}^{d}$ and $y_{j i}^{d}$.

${ }^{42}$ The existence and uniqueness issue of such equilibrium has been discussed in McAdams ('04) and Lizzeri \& Persico ('00).
} 


\subsection{Identification Proofs}

\section{Proof. of Lemma 4}

a) The proof is very similar to the proof of Campo, Perrigne \& Vuoung ('02). The only difference is that we are identifying the expected ex-ante interdependent values here and not the private values. Let the joint distribution of bids from the asymmetric drainage auction be $G($.$) with the support [\underline{b}, \bar{b}]^{n}$. Let there be two distributions of private values $F_{d}($.$) and \widetilde{F}_{d}($.$) leading to the same joint distribution of bids. Let b_{1}^{d}(., F)$ and $b_{0}^{d}(., F)$ and $\widetilde{b}_{1}^{d}(., F), \widetilde{b}_{0}^{d}(., F)$ be the strictly increasing Bayesian equilibrium strategies corresponding to $F_{d}($.$) and \widetilde{F}_{d}($.$) respectively. Therefore they satisfy the first order differential equations. Hence$

$$
\begin{aligned}
& F\left(v_{1}^{d}, v_{0}^{d}\right)=\operatorname{Pr}\left(\xi_{1}^{d}\left(b_{1}^{d}, G\right) \leq v_{1}^{d}, \xi_{0}^{d}\left(b_{0}^{d}, G\right) \leq v_{0}^{d}\right)=G\left(\xi_{1}^{d^{-1}}\left(s_{1}^{d}, G\right), \xi_{0}^{d^{-1}}\left(s_{0}^{d}, G\right)\right) \\
& \widetilde{F}\left(v_{1}^{d}, v_{0}^{d}\right)=\operatorname{Pr}\left(\xi_{1}^{d}\left(b_{1}^{d}, G\right) \leq v_{1}^{d}, \xi_{0}^{d}\left(b_{0}^{d}, G\right) \leq v_{0}^{d}\right)=G\left(\xi_{1}^{d^{-1}}\left(s_{1}^{d}, G\right), \xi_{0}^{d^{-1}}\left(s_{0}^{d}, G\right)\right)
\end{aligned}
$$

Hence $F\left(v_{1}^{d}, v_{0}^{d}\right)=\widetilde{F}\left(v_{1}^{d}, v_{0}^{d}\right)$ on their common support $\left[\underline{v}_{1}^{d}, \bar{v}_{0}^{d}\right]^{n} \doteq\left[\xi_{0}^{d}\left(\underline{b}^{d}, G\right), \xi_{1}^{d}\left(\bar{b}^{d}, G\right)\right]^{n}$. Hence the asymmetric affiliated interdependent values of the drainage auction is identified.

\section{Proof. of Lemma 5}

First note that by lemma (b) on the identification of the drainage auction, the third term is identified from data on drainage auctions. Now recall that for the two bidder case, we had,

$$
\begin{aligned}
G_{B_{w} \mid b_{i}^{w}}^{w}\left(y \mid b_{i}^{w}\right) & =M_{Y_{w} \mid s_{w}}\left(Y_{w} \mid s_{i}^{w}\right)+\operatorname{Pr}\left(\alpha_{-i}=0 \mid s_{i}^{w}\right) \\
& =M_{Y_{w} \mid s_{w}}\left(\phi\left(B_{w}\right) \mid \phi\left(b_{i}^{w}\right)\right)+\operatorname{Pr}\left(\alpha_{-i}=0 \mid \phi\left(b_{i}^{w}\right)\right) \\
& =\operatorname{Pr}\left(\alpha_{-i}=1 \mid s_{i}^{w}\right) F^{w}\left(\phi\left(b_{-i}^{w}\right)\right)+\operatorname{Pr}\left(\alpha_{-i}=0 \mid \phi\left(b_{i}^{w}\right)\right)
\end{aligned}
$$

A straightforward generalization of the above for the $N$ bidder case is

$$
G_{B_{w} \mid b_{i}^{w}}^{w}\left(y \mid b_{i}^{w}\right)=\sum_{j \neq i} \operatorname{Pr}\left(\alpha_{j}=1 \mid s_{i}^{w}\right) F^{w}\left(\phi\left(b_{-i}^{w}\right)\right)+\operatorname{Pr}\left(\alpha_{j}=0 \mid \phi\left(b_{i}^{w}\right), \text { for all } j\right)
$$

Since $G_{B_{w} \mid b_{i}^{w}}^{w}\left(y \mid b_{i}^{w}\right)$ and $\operatorname{Pr}\left(\alpha_{j}=2 \mid s_{i}^{w}\right)$ and $\operatorname{Pr}\left(\alpha_{j}=1 \mid s_{i}^{w}\right)$ are observable from the observed data on bids and entry behavior, $F^{w}\left(\phi\left(b_{-i}^{w}\right)\right)$ is identified. Hence the expected common value component $U$ is identified using the first order condition.

\subsection{Estimation Strategy}

\section{First Stage}

Note that, the inverse hazard rate $\left(\right.$ haz $\left._{0}\right)$ ratio in 11 can be interpreted as,

$$
\begin{aligned}
h a z_{0} & =\frac{\operatorname{Pr}\left(B_{1}^{d} \leq b_{0}, B_{0}^{d} \leq b_{0}, b_{0}=b_{0}\right)}{\operatorname{Pr}\left(B_{1}^{d}=b_{0}, B_{0}^{d} \leq b_{0}, b_{0}=b_{0}\right)+\operatorname{Pr}\left(B_{1}^{d} \leq b_{0}, B_{0}^{d}=b_{0}, b_{0}=b_{0}\right)} \\
& =\frac{G_{B^{d}, B_{0}^{d}, b_{0}^{d}\left(b_{0}^{d}, b_{0}^{d}, b_{0}^{d}\right)}^{D_{01}\left(b_{0}^{d}, b_{0}^{d}, b_{0}^{d}\right)+D_{02}\left(b_{0}^{d}, b_{0}^{d}, b_{0}^{d}\right)}}{}
\end{aligned}
$$


Let $L$ be the number of auctions and $K($.$) be a kernel. Note that the term G_{B_{1}^{d}, B_{0}^{d}, b_{0}^{d}}(x, y, z)$ can be estimated as

$$
G_{B_{1}^{d}, B_{0}^{d}, b_{0}^{d}}(x, y, z)=\frac{1}{h_{g_{1}} L} \sum_{l=1}^{L} \frac{1}{n_{0}^{d}} \sum_{i=1}^{n_{1}^{d}} 1\left(B_{0 i l}^{d} \leq x\right) 1\left(B_{0 l}^{d} \leq y\right) K_{G}\left(\frac{z-b_{0 i l}}{h_{g_{1}}}\right)
$$

Similarly $G_{B_{0}^{d}, b_{0}^{d}}\left(b_{1}^{d}, b_{1}^{d}\right)$ can be estimated as,

$$
G_{B_{0}^{d}, b_{0}^{d}}(x, z)=\frac{1}{h_{g_{0}} L} \sum_{l=1}^{L} 1\left(B_{0 l}^{d} \leq y\right) K\left(\frac{z-b_{1 i l}}{h_{g_{0}}}\right)
$$

The denominators of 11 can be estimated as,

$$
\begin{aligned}
& \widehat{D}_{01}(x, y, z)=\frac{1}{h_{g_{01}}^{2} L} \sum_{l=1}^{L} \frac{1}{n_{0}^{d}} \sum_{i=1}^{n_{0}^{d}} K\left(\frac{x-B_{1 i l}^{d}}{h_{g_{1}}}\right) 1\left(B_{0 l}^{d} \leq y\right) K\left(\frac{z-b_{0 i l}}{h_{g_{1}}}\right) \\
& \widehat{D}_{02}(x, y, z)=\frac{1}{h_{g_{0}}^{2} L} \sum_{l=1}^{L} \frac{1}{n_{0}^{d}} \sum_{i=1}^{n_{0}^{d}} 1\left(B_{1 i l}^{d} \leq x\right) K\left(\frac{y-B_{0 i l}^{d *}}{h_{g 0}}\right) K\left(\frac{z-b_{0 i l}}{h_{g_{0}}}\right)
\end{aligned}
$$

Similarly for 10 ,we have

$$
\widehat{D}_{11}(x, y)=\frac{1}{h_{g_{01}}^{2} L} \sum_{l=1}^{L} K\left(\frac{x-b_{1 i l}}{h_{g_{1}}}\right) K\left(\frac{y-b_{1 i l}}{h_{g_{1}}}\right)
$$

Therefore the pseudo values from the drainage auctions are estimated as,

$$
\begin{gathered}
\widehat{v}_{1}^{d}\left(s_{1}^{d}, s_{1}^{d}\right)=b_{1}^{d}+\frac{\widehat{G}_{B_{0}^{d}, b_{1}^{d}}\left(b_{1}^{d}, b_{1}^{d}\right)}{\widehat{D}_{11}\left(b_{1}^{d}, b_{1}^{d}\right)}=\widehat{\xi}_{1}^{d}\left(b_{1}^{d}, G\right) \\
=b_{1}^{d}+h a z_{1}^{d} \\
\widehat{v}_{0}^{d}\left(s_{0}^{d}, s_{0}^{d}\right)=b_{0}^{d}+\frac{\widehat{G}_{B^{d}, B_{0}^{d}, b_{0}^{d}}\left(b_{0}^{d}, b_{0}^{d}, b_{0}^{d}\right)}{\widehat{D}_{01}\left(b_{0}^{d}, b_{0}^{d}, b_{0}^{d}\right)+\widehat{D}_{02}\left(b_{0}^{d}, b_{0}^{d}, b_{0}^{d}\right)}=\widehat{\xi}_{0}^{d}\left(b_{0}^{d}, G\right) \\
=b_{0}^{d}+h a z_{0}^{d}
\end{gathered}
$$

We plug these pseudo values into the objective function to get back the equilibrium value function for the strong and weak bidders respectively. More specifically, we need to estimate

$$
\begin{aligned}
T_{1}(1 \text { is strong }) & =\int \max _{b_{D} \geq 0}\left\{\left(v_{1}\left(s_{1}^{d}, s_{0}^{d}\right)-b_{1}\right) \times \operatorname{Pr}\left(b_{0} \leq b_{1}\right)\right\} d F\left(s_{1}^{d}, D=1\right) \\
& \leq \int\left\{\left(v_{1}\left(s_{1}^{d}, s_{1}^{d}\right)-b_{1}^{*}\right) \times \operatorname{Pr}\left(b_{0} \leq b_{1}\right)\right\} d F\left(s_{1}^{d}, D=1\right)
\end{aligned}
$$

where $b_{1}^{*}$ is the optimum bid and the inequality follows from the assumption that $v_{1}(x, y) \leq v(x, x)$, for all $y \leq x$.

Now,

$$
\left(v_{1}\left(s_{1}^{d}, s_{1}^{d}\right)-b_{1}\right) \times \operatorname{Pr}\left(b_{0}^{d} \leq b_{1}^{d}\right)=\frac{G_{B_{1}^{d}, B_{0}^{d} \mid b_{1}^{d}}(X, X \mid x)}{d G_{B_{1}^{d}, B_{0}^{d} \mid b_{1}^{d}}(X, X \mid x) / d X} \times G_{B_{1}^{d}, B_{0}^{d} \mid b_{1}^{d}}(X, X \mid x)
$$


$\Rightarrow$

$$
T_{1}(1 \text { is strong }) \leq \int \frac{G_{B^{d}, B_{0}^{d} \mid b_{1}^{d}}(X, X \mid x)}{d G_{B_{1}^{d}, B_{0}^{d} \mid b_{1}^{d}}(X, X \mid x) / d X} \times G_{B_{1}^{d}, B_{0}^{d} \mid b_{1}^{d}}(X, X \mid x) f_{1}\left(s_{1}^{d}\right) d s_{1}^{d}
$$

Now,

$$
f_{1}(.) \frac{\partial b^{-1}(b)}{\partial b}=g_{1}(b)
$$

and

$$
\frac{\partial b^{-1}(b)}{\partial b}=\frac{1}{\frac{\partial b(s)}{\partial s}}
$$

By substituting, we get

$$
\begin{aligned}
T_{1}(1 \text { is strong }) & \leq \int \frac{G_{B_{1}^{d}, B_{0}^{d} \mid b_{1}^{d}}(X, X \mid x)}{d G_{B_{1}^{d}, B_{0}^{d} \mid b_{1}^{d}}(X, X \mid x) / d X} \times G_{B_{1}^{d}, B_{0}^{d} \mid b_{1}^{d}}(X, X \mid x) g_{1}\left(b_{1}\right) d b_{1} \\
& =\widehat{T}_{1}
\end{aligned}
$$

where $g\left(b_{1}\right)$ is the density of $b_{1}$.

Similarly,

$$
\begin{aligned}
T_{0}(1 \text { is weak }) & \leq \int \frac{G_{B_{1}^{d}, B_{0}^{d} \mid b_{1}^{d}}\left(b_{1}^{d}, b_{1}^{d} \mid b_{1}^{d}\right)}{d G_{B_{1}^{d}, B_{0}^{d} \mid b_{1}^{d}}\left(b_{0}^{d}, b_{0}^{d} \mid b_{0}^{d}\right) / d X} \times G_{B_{1}^{d}, B_{0}^{d} \mid b_{1}^{d}}\left(b_{1}^{d}, b_{1}^{d} \mid b_{1}^{d}\right) g_{0}\left(b_{0}\right) d b_{0} \\
& =\widehat{T}_{0}
\end{aligned}
$$

The bid distributions functions are estimated non-parametrically as described above and the integration is evaluated numerically.

Note that, the bidders must make nonzero expected profits, otherwise they can always bid zero and make zero profit. Hence $T_{1}() \geq$.0 and $T_{0}() \geq$.0 . Therefore, $T_{1}()-.T_{0}(.) \leq T_{1}($.$) . Since T_{1}(.) \leq \widehat{T}_{1}$, as shown above, an upper bound of the value of information: $T_{1}()-.T_{0}($.$) is \widehat{T}_{1}\left(\right.$ as $\left.T_{1}()-.T_{0}(.) \leq T_{1}(.) \leq \widehat{T}_{1}\right)$. Hence $\widehat{T}_{1}$ is the upper bound of the value of information. Note that, in case of private values, the value of information is exactly $\widehat{T}_{1}-\widehat{T}_{0}$.

\section{Second Stage}

In the second stage we first non parametrically estimate the bid distributions for each wildcat sales $G^{w}$ and $g^{w}$ respectively. We then plug these and bounds of $T_{1}$ and $T_{0}$ in the following first order equation characterizing the equilibrium, to get the lower bound of the 'pseudo' values,

$$
\begin{aligned}
U & =b_{i}^{w}+\frac{G_{B^{w} \mid s^{w}}^{w}\left(b_{i}^{w} \mid b_{i}^{w}\right)}{g_{B^{w} \mid s^{w}}^{w}\left(b_{i}^{w} \mid b_{i}^{w}\right)}-\beta\left[T_{1}-T_{0}\right] \\
& \geq b_{i}^{w}+\frac{G_{B^{w} \mid s^{w}}^{w}\left(b_{i}^{w} \mid b_{i}^{w}\right)}{g_{B^{w} \mid s^{w}}^{w}\left(b_{i}^{w} \mid b_{i}^{w}\right)}-\beta \widehat{T}_{1} \\
& =\widehat{U}
\end{aligned}
$$

The value of information as a proportion of the common value $U$ can be written as, 


$$
\frac{\beta\left[T_{1}-T_{0}\right]}{U} \leq \frac{\beta \widehat{T}_{1}}{U} \leq \frac{\beta \widehat{T}_{1}}{\widehat{U}}
$$

Thus, the estimated right hand side gives us an estimate of the upper bound of the value of information, as a proportion of first period's value in the wildcat auction.

\subsection{Affiliation (Total Positivity)}

The concept of affiliation as coined by Milgrom \& Weber ('82), is what is known as Total Positivity (TP) in statistical literature. More specifically the variables $\mathbf{s}=\left(s_{1}, s_{2}, . . s_{n}\right)$ are said to be affiliated if for all $\mathbf{s}^{\prime}, \mathbf{s}^{\prime \prime} \in S$,

$$
f\left(\mathbf{s}^{\prime} \wedge \mathbf{s}^{\prime \prime}\right) f\left(\mathbf{s}^{\prime} \vee \mathbf{s}^{\prime \prime}\right) \geq f\left(\mathbf{s}^{\prime}\right) f\left(\mathbf{s}^{\prime \prime}\right)
$$

where $\left(\mathbf{s}^{\prime} \vee \mathbf{s}^{\prime \prime}\right)=\left(\max \left(s_{1}^{\prime}, s_{1}^{\prime \prime}\right), \max \left(s_{2}^{\prime}, s_{2}^{\prime \prime}\right), \ldots, \max \left(s_{n}^{\prime}, s_{n}^{\prime \prime}\right)\right)$, and $\left(\mathbf{s}^{\prime} \wedge \mathbf{s}^{\prime \prime}\right)=\left(\min \left(s_{1}^{\prime}, s_{1}^{\prime \prime}\right), \min \left(s_{2}^{\prime}, s_{2}^{\prime \prime}\right), \ldots, \min \left(s_{n}^{\prime}, s_{n}^{\prime \prime}\right)\right)$ are the component wise maximum and minimum of $\mathbf{s}^{\prime}$ and $\mathbf{s}^{\prime \prime}$.

For two variables, $s_{1}^{\prime} \geq s_{1}, s_{2}^{\prime} \geq s_{2}$, $\Rightarrow$ the above condition boils down to $f\left(s_{1}^{\prime}, s_{2}\right) f\left(s_{1}, s_{2}^{\prime}\right) \leq f\left(s_{1}, s_{2}\right) f\left(s_{1}^{\prime}, s_{2}^{\prime}\right)$,equivalently,

$$
\frac{f\left(s_{2}^{\prime} \mid s_{1}\right)}{f\left(s_{2} \mid s_{1}\right)} \leq \frac{f\left(s_{2}^{\prime} \mid s_{1}^{\prime}\right)}{f\left(s_{1} \mid s_{1}^{\prime}\right)}
$$

i.e., $\frac{f\left({ }^{\prime} \mid s_{1}^{\prime}\right)}{f\left(. \mid s_{1}\right)}$ is increasing in $s_{1}$ : which is called the monotone likelihood ratio property.Thus higher values of $s_{1} \Rightarrow$ higher values of $s_{2}$ more likely

Taking logarithms to the affiliation inequality $f\left(s_{1}^{\prime}, s_{2}\right) f\left(s_{1}, s_{2}^{\prime}\right) \leq f\left(s_{1}, s_{2}\right) f\left(s_{1}^{\prime}, s_{2}^{\prime}\right)$ and setting $\log 0 \rightarrow$ $-\infty$, we get, $\log \left(f\left(s_{1}, s_{2}\right)+\log f\left(s_{1}^{\prime}, s_{2}^{\prime}\right) \leq \log f\left(s_{1}^{\prime}, s_{2}\right)+\log f\left(s_{1}, s_{2}^{\prime}\right)\right.$. This property of $f($.$) is called \log$ supermodularity. The proof of the following simple characterization of log supermodularity can be found in Topkis ('98).

Theorem 6 If $f$ is positive and twice continuously differentiable, then $f$ is log supermodular if and only if $\frac{\partial^{2}}{\partial s_{i} \partial \mathbf{s}_{j}} \ln f \geq 0$.

Hence random variables $s_{i}$ and $s_{j}$ with density function $f($.$) are affiliated if and only if \frac{\partial^{2}}{\partial s_{i} \partial \mathbf{s}_{j}} \ln f \geq 0$.

For more details see MW.

\subsection{Copulas}

Definition 7 A copula is the distribution function of a random vector in $\Re^{n}$ with uniform $(0,1)$ - marginals. Alternatively a copula is a function $C:[0,1]^{n} \rightarrow[0,1]$ which has these properties:

1. $C\left(v_{1}, v_{2}, \ldots, v_{n}\right)$ is increasing in each component $v_{i}$.

2. $C\left(1,1, . v_{i}, . ., 1\right)=v_{i}$ for all $i \in\{1, \ldots, n\}, v_{i} \in[0,1]$.

Below, for simplicity, we discuss properties for $n=2$. 
Theorem 8 (Sklar's) Let $F$ be a joint distribution function with marginals $F_{1}$ and $F_{2}$. Then there exists a copula $C$ such that for all $x, y \in \Re$,

$$
F\left(v_{1}, v_{2}\right)=C\left(F_{1}\left(v_{1}\right), F_{2}\left(v_{2}\right)\right)
$$

If $F_{1}$ and $F_{2}$ are continuous then $C$ is unique; otherwise $C$ is uniquely determined on $R a n F_{1} \times R a n F_{2}$. Conversely, if $C$ is a copula and $F_{1}$ and $F_{2}$ are distribution functions, then the function $F(.,$.$) defined above$ is a joint distribution function with margins $F_{1}$ and $F_{2}$.

Theorem 9 If $\left(v_{1}, v_{2}\right)$ has copula $C$ and $T_{1}$ and $T_{2}$ are increasing continuous functions, then $\left(T_{1}\left(v_{1}\right), T_{2}\left(v_{2}\right)\right)$ also has copula $C$.

Below the order in copulas is defined.

Definition 10 Let $C_{1}$ and $C_{2}$ be copulas, we say that $C_{1}$ is smaller than $C_{2}\left(C_{2} \succeq C_{1}\right)$, if $C_{1}\left(v_{1}, v_{2}\right) \leq$ $C_{2}\left(v_{1}, v_{2}\right)$.

Below we present a special group of copulas called Archimedean copulas. Archimedean copulas are those distribution functions $F\left(v_{1}, v_{2}\right)$, such that $F\left(v_{1}, v_{2}\right)=\tau^{-1}\left[\tau\left(v_{1}\right)+\tau\left(v_{2}\right)\right]$ for some convex, decreasing function $\tau$.

Copulas can thus be thought of as a form of the utility function. A bivariate copula depicts the relationships between two random variables, same as an utility function expresses the dependence between two goods, parametrically represented by the marginal rate of substitution. For example, consider the following two copulas, $C\left(v_{1}, v_{2}\right)=v_{1}+v_{2}-1=W\left(v_{1}, v_{2}\right)$ and $C\left(v_{1}, v_{2}\right)=\min \left(v_{1}, v_{2}\right)=M\left(v_{1}, v_{2}\right)$. It can be shown that for every copula $C$ and every $\left(v_{1}, v_{2}\right) \in[0,1]^{2} ; W\left(v_{1}, v_{2}\right) \leq C\left(v_{1}, v_{2}\right) \leq M\left(v_{1}, v_{2}\right)$

If we are thinking copulas as utility functions then $W\left(v_{1}, v_{2}\right)$ represents perfect substitutes and $M\left(v_{1}, v_{2}\right)$ represents perfect complements and all relationships between two goods falls in between these two. The bounds above is called the Frechet-Hoeffding bounds in copula literature (see Nelson('99)). Since we have drawn the analogy of copulas to utility functions here is one nice property of Archimedean copulas.

Theorem 11 The level curves of an Archimedean copula are convex.

We give below some Archimedean copulas and their major properties

\begin{tabular}{lcccc}
\hline \hline Copula & $C\left(v_{1}, v_{2}\right)$ & $\tau(v)$ & Range of $\alpha$ & Total Positivity \\
\hline Frank & $\log _{\alpha}\left[1+\frac{\left(\alpha^{v_{1}}-1\right)\left(\alpha^{v_{2}}-1\right)}{(\alpha-1)}\right]$ & $\log _{\alpha}\left(\frac{1-\alpha}{1-\alpha^{s}}\right)$ & {$[0, \infty)$} & Yes \\
Clayton & $\left(v_{1}^{-\alpha}+v_{2}^{-\alpha}-1\right)^{\frac{1}{\alpha}}$ & $\frac{v^{-\alpha}-1}{\alpha}$ & {$[0, \infty)$} & Yes \\
Gumbel-Hugard & $\left.\exp \left(-\left[\left(-\log v_{1}\right)^{\alpha}+\left(-\log v_{2}\right)^{\alpha}\right)\right]^{1 / \alpha}\right)$ & {$[-\log (v)]^{\alpha}$} & {$[1, \infty)$} & Yes \\
\hline
\end{tabular}

It is easy to verify that for the above Archimedean copulas, $\frac{\partial^{2}}{\partial v_{1} \partial \mathbf{v}_{2}} \ln c \geq 0$ hence they are affiliated by Theorem (6) above,where $c$ is the density of the copula function $C$. There is a unique mapping between copulas and Kendall's $\tau$, given by 


$$
\tau_{X Y}=\iint 4 C(u, v) d C(u, v)-1
$$

For example, for Clayton copulas, the above equality reduces to $\tau_{\alpha}=\frac{\alpha}{\alpha+2}$. A goodness of fit test of which copula family to be used can be constructed using the above characterization. The idea is simple, since for Archimedean copulas the copula function and hence the copula family has a unique representation in terms of Kendall's $\tau$; the copula function which minimizes the distance between the observed $\tau$ from actual data and $\tau$ driven by the above relationship should be used. For more analysis see Gupta ('04).

\subsection{Graphs}


Figure 2 : Actual vs Estimated Densities

Solid Line: Actual, Dotted Line: Estimated,

Grey Region: 95\% Confidence Band 
Figure: 3 
Figure: 4 
Figure 5: Strong vs Weak Bidder's Densities

2 Bidders, Solid Line: Strong Bidder, Dotted Line: Weak Bidder, Grey Region: 95\% Confidence Band 
Figure: 6 Strong vs Weak Bidder Densities: 3 Bidders 
Figure: 7 
Figure: 8 Wildcat Auction Bidder Densities 


\section{References}

[1] Arnold, B.C., N. Balakrishnan, and H.N. Nagaraja (1992) "A First Course in Order Statistics" New York: John Wiley \& Sons.

[2] Athey, S. (2000) "Single Crossing Properties and the Existence of Pure Strategy Equilibria in Games of Incomplete Information" Econometrica, 69, 861-890.

[3] Athey, S. and P. Haile (2002) "Identification of Standard Auction Models" Econometrica, 70, 2107-2140.

[4] Athey, S. and Levine J. (2001) "The value of Information in Monotone Decision Problems" Working paper, Stanford University.

[5] Bajari, P. and Hortacsu, A. (2002) "Auction Models when Bidders Make Small Mistakes: Evidence from Theory and Estimation" working Paper.

[6] Berry, S. (1992) "Estimation of a Model of Entry in the Airline Industry" Econometrica, 60, 889-917.

[7] Betton, S., B. E. Eckbo and K. S. Thorburn (2005), The toehold puzzle, Working Paper (Concordia University; Dartmouth College).

[8] Bhattacharya, R.N. and M. Majumdar (1989) "Controlled Semi-Markov Models- The Discounted Case" Journal of Statistical Planning and Inference, 21, 365-381.

[9] Boone, A., and H. Mulherin (2003), Corporate restructuring and corporate auctions, Working paper (College of William and Marry; Claremont McKenna College).

[10] Boone, A., and H.Mulherin (2006a), How are firms sold?, Journal of Finance, forthcoming.

[11] Boone, A. and H. Mulherin (2006b), Do auctions induce a winner's curse? New Evidence from the corporate takeover market, Working Paper, University of Georgia.

[12] Brenstrup B. and Harry Paarsch (2004) "Semiparametric Identification and Estimation in Multi-Object, Sequential, English Auctions" working Paper, University of Iowa.

[13] Bulow J., M. Huang, and P. Klemperer (1999), Toeholds and takeovers, Journal of Political Economy $107,427-454$.

[14] Campo, S. Perrigne, I. and Vuong, Q. (2003) "Asymmetry in First Price Auctions with Affiliated Private Values" Journal of Applied Econometrics,179-207.

[15] Chen X and Y.Fan (2002) "Estimation of Copula Based Time Series Modesl" Working Paper. NYU

[16] Dasgupta, S. and R Hansen (2006) "Auctions in Corporate Finance" Handbook of Corporate Finance: Empirical Corporate Finance" North- Holland, Handbook in Finance Series.

[17] Dasgupta, S., and K. Tsui (2003), A "matching auction" for targets with heterogeneous bidders, Journal of Financial Intermediation 12, 331-364. 
[18] Dasgupta, S., and K. Tsui (2004), Auction with cross-shareholdings, Economic Theory 24, 163-194.

[19] Eckbo, B. E., R. Giammarino and R. Heinkel (1990), Asymmetric information and medium of exchange in takeovers: theory and tests, Review of Financial Studies 3, 651-675.

[20] French, K. R., and R. E. McCormick (1984), Sealed bids, sunk costs, and the process of competition, Journal of Business 57, 417-441.

[21] Embrechts, P. A. Mcneil and D. Straumann (2001) "Correlation and Dependence in Risk Management: Properties and Pitfalls" Working Paper.

[22] Genset, C.(1987) "Frank's Family of Bivariate Distributions," Biometrika, 74 (3), 549-555

[23] Genset, C.and L.P. Rivest (1993) "Statistical Inference Procedure for Bivariate Archimedean Copulas," Journal of the American Statistical Association, 88 (423), 1034-1043.

[24] Genset, C. K. Ghoudi, and L.P. Rivest (1995) "A Semiparametric Estimation Procedure of Dependence Parameters in Multivariate Families of Distributions," Biometrika, 82(3), 543-552.

[25] Genset, C. (1987) "A Semiparametric Estimation Procedure of Dependence Parameters in Multivariate Families of Distributions," Biometrika, 82(3), 543-552.

[26] Guerre, E., Perrigne, I., and Vuong,Q. (2000) "Optimal Nonparametric Estimation of First Price Auctions", Econometrica, 68,525-574.

[27] Gupta, S. (2003) "Endogenous Asymmetry and Entry in Sequential Multi-Object Auctions", Working Paper.

[28] Gupta, S. (2004) "A Copula Based Semi-Parametric Estimation and Testing of First Price Auctions" Working Paper.

[29] Gupta, S. (2002) "Adaptive Learning in Discrete Choice Dynamic Programming Problems" Working Paper.

[30] Haile,P., Hong,H. and Shum,M. (2002) "Non-parametric Tests for Common Values in First-Price Sealed Bid Auctions" Working Paper, Unoversity of Wisconsin- Madison.

[31] Hansen, R. G. (2001), Auction of companies, Economic Inquiry 39, 30-43.

[32] Hendricks K. and R. Porter (1988) "An Empirical Study of an Auction with Asymmetric Information" American Economic Review, pp.865-883.

[33] Hendricks K, R. Porter and B. Boudreau (1987) "Information, Returns, and Bidding Behavior in OCS Auctions: 1954-1969" Journal of Industrial Economics, pp 517-542.

[34] Hendricks K, R. Porter and G. Tan (1993) "Optimal Selling Strategies for Oil and Gas Leases with an Informed Buyer" American Economic Review: Papers and Procedings, pp 234-239. 
[35] Hendricks,K., Pinkse,J., and Porter, R.(2002) "Empirical Implication of Equilibrium Bidding in FirstPrice, Symmetric, Common Value Auctions" working Paper

[36] Jofre-Bonet, Maria and M. Pesendorfer (2003) "Estimation of a Dynamic Auction Game" forthcoming Econometrica.

[37] Kagel, J. \& D. Levin (2002) "Common Value Auctions and The Winner's Curse" Princton University Press.

[38] Laffont J.J., H. Oscard and Q. Vuoung (1995) "Econometrics of First Price Auctions", Econometrica, 63, 958-980

[39] Lebrun, B. (1999) "First Price Auctions in the Asymmetric N Bidder Case" International Economic Review, 40, 125-142.

[40] Lehmann E.L. (1988) "Comparing Location Experiments" The Annals of Statistics, 16, pp.521-533.

[41] Li, T., Perrigne, I. and Vuong, Q. (2002) "Structural Estimation of the Affiliated Private Values Auction Model" Rand Journal of Economics,33, 171-193

[42] Li, T., Perrigne,I. and Vuong, Q. (2000) "Conditionally Independent Private Information in OCS Wildcat Auctions" Journal of Econometrics, 98, 129-161.

[43] Maskin, E. and Riley, J. (1996) "Uniqueness of Equilibrium in Asymmetric Auctions" working paper,

[44] Maskin, E. and Riley, J. (2000a) "Asymmetric Auctions" Review of Economic Studies, 67, 413-438.

[45] Maskin, E. and Riley, J. (2000b) "Equilibrium in Sealed High Bid Auctions" Review of Economic Studies, 67, 439-454.

[46] McAdams David (2004a) "Characterizing Equilibria in Asymmetric First Price Auction" Working paper, MIT.

[47] McAdams David (2004b) “Uniqueness of Equilibrium in Symmetric First Price Auction" Working paper, MIT.

[48] Mcaffe,P. Quan,D. Vincent, D. (2002) "How to Set Minimum Acceptable Bids, with an Application to Real Estate Auctions", Journal of Industrial Economics, Dec. pp 391.

[49] Mcaffe,P.and Vincent, D. (1992) "Updating the Reserve Price in Common-Value Auctions", American Economic Review, May. pp 512-518.

[50] Mcaffe,P. McMillan (1987) "Auction with Entry"

[51] McKelvey and Palfrey (1995) "Quantal Response Equilibrium for Normal form Games" Games and Economic Behavior, 10(1) pp.6-38. 
[52] Milgrom \& Weber (1982) "A Theory of Auctions and Competitive Bidding", Econometrica, 50(5), pp 1089-1122.

[53] Persico N. (2000) "Information Acquisition in Auctions" Econometrica, 68, pp.135-148.

[54] Nelson, R. (1997) "An Introduction to Copulas" Springer.

[55] Porter R. (1995) "The Role of Information in US Oil and Gas Lease Auction" Econometrica, 63, pp.1-27.

[56] Povel, P. and R. Singh, "Takeover Contests with Asymmetric Bidders", Review of Financial Studies, forthcoming.

[57] Pinkse J. and G. Tan (2005) " The Affiliation Effect in First Price Auctions" Econometrica, (73), pp. 263-277.

[58] Rao, B.L.S.P. (1992) "Identifiability in Stochastic Models: Characterization of Probability Distributions" Academic Press, New York.

[59] Reny P. Shmuel Zamir (2002) "On the existence of Pure Strategy Monotone Equilibria in Asymmetric First Price Auction" Working Paper, Unversity of Chicago.

[60] Roll, R.(1986), The Hubris hypothesis of corporate takeovers, Journal of Business 59, 197-216.

[61] Rust John (1994) "Estimation of Dynamic Structural Models, Problems and Prospects: Discrete Decision Processes" in Advances in Econometrics, edited by Christopher Sims, Sixth World Congress, pp119-170.

[62] Seim, Katja (2003) “An Empirical Model of Firm Entry with Endogeneous Product- Type Choices" Working paper, Stanford University.

[63] Singh, R. (1998), Takeover bidding with toeholds: the case of owners curse, Review of Financial Studies 11, 679-704.

[64] Virag Gabor (2004) "Repeated Common Value Auctions" Working Paper, University of Rochester. 